\title{
Aging and the Financing of Social Security in Switzerland
}

\author{
Christian Keuschnigg ${ }^{a}$, Mirela Keuschnigg ${ }^{\text {}}$, and Christian JaAg ${ }^{c}$
}

JEL-Classification: D58, D91, H55, J26, J64

Keywords: aging, social security, retirement, human capital, unemployment

\section{Introduction}

Demographic change poses a challenge to the welfare state. With current levels of benefits and a much larger dependent population, contribution rates and social spending will need to grow to unprecedented levels. Already now, social spending is a main driver of public sector growth in Switzerland. The size of the public sector expanded from 26.2\% of GDP in 1990 to $30.2 \%$ in 2007. The prime reason is spending on social insurance which grew from $7.2 \%$ to $10.8 \%$ of GDP (see Bundesrat, 2008). Given the projected rise in the dependency ratio, this trend is bound to accelerate over several decades if current policies remain unreformed. The burden of labor taxes and social security contributions would have to grow much larger, with negative consequences for labor market performance. Since contributions to social insurance are basically proportional, they impose a substantial tax/contribution burden in the low and medium income tax brackets even if the income tax burden is low.

The financing of social insurance and labor market behavior are importantly interrelated. Aging necessitates higher taxes and contributions with negative effects on labor earnings and growth. Lower earnings, in turn, require further increases in contribution rates and labor taxes. The present paper focuses on the incentive effects on five margins of labor market behavior in general equilibrium. First, employees can adjust intensive labor supply, consisting of hours worked

a Prof. Dr., University of St. Gallen (FGN-HSG), Switzerland, CEPR, CESifo and NetSpar. Financial support by the Swiss State Secretariat for Economic Affairs (SECO) is gratefully acknowledged. We appreciate stimulating comments by SECO economists, seminar participants at the University of St. Gallen and Hannes Berger and Ludwig Strohner. We are particularly grateful for very constructive comments by an anonymous referee and by the editor, Klaus Neusser.

b Dr., University of St.Gallen (FGN-HSG), Switzerland.

c Dr., Swiss Economics, Switzerland. 
or effort on the job. This incentive is measured by the effective tax rate on wage income which includes not only the income tax but also contributions to social security as well as consumption taxes. In principle, the contributions to social security are a non-distortive price for individual insurance. However, the insurance benefits are typically worth less than contribution payments. As was first pointed out by FELDSTEIN and SAMWICK (1992), part of the statutory contribution rate is an implicit tax which adds to the general wage tax burden. Many economic studies confine attention to this intensive margin of labor supply.

The size and quality of aggregate employment may depend, in fact, rather more on other margins of labor supply. Second, employees may invest in education and life-time training to improve their skills. A progressive income tax tends to discourage training since the extra tax on higher future earnings is larger than the tax savings today when the individual gives up income to devote more time to training. On the other hand, the government often directly subsidizes current training costs. Training incentives are also importantly linked to policy in an aging society. Encouraging postponed retirement not only raises labor force participation among older workers, but also strengthens incentives for training among prime age workers as they can expect to consume the returns to training over a longer active working life.

Third, taxes and benefits influence individual decisions to enter the labor market and, thereby, affect participation rates among prime age workers. The larger the net of tax labor income from active employment is relative to the generosity of social assistance, the larger is the incentive to (re-)enter the labor market. Fiscal incentives are captured by so-called 'participation tax rates' which are typically large since they consist of the sum of tax and contribution rates and the replacement rate of social income when out of the labor force. Fourth, the incentives of unemployed persons to search for jobs are diminished by wage taxes and contribution payments as well as by foregone benefits and assistance payments when leaving unemployment. Finally, an individual's actual retirement date to a large part reflects a participation decision as well. When postponing retirement and continuing work, a person pays taxes and social security contributions over a longer period and, at the same time, may have to give up an eligible pension. Again, the participation tax on continued work tends to be very high since it consists of the sum of taxes and foregone pension benefits. However, the incentives for early retirement can be much reduced if the system includes significant pension discounts/supplements to punish/reward individuals for retiring earlier/later.

This paper aims to quantify the potential economic impact of aging in Switzerland. To this end, we use a computational overlapping generations model to 
replicate demographic projections and to quantify the fiscal and economic consequences. In particular, the model captures in detail the interactions between taxes, social security and the labor market. As a base case scenario, we simulate the consequences of a passive fiscal strategy which merely adjusts labor taxes and contribution rates to keep public budgets balanced. In line with existing literature, the economic consequences turn out rather discouraging, leading to an increase in the total labor tax burden by 21 percentage points and a reduction in per capita income of roughly 20 percent. We then turn to a comprehensive reform proposal which implements six important policy measures, ranging from structural reform of the pay-as-you-go (PAYG) pillar to an increase in the statutory retirement age. Raising retirement age by effectively four years is by far the most important measure. The simulation results show that the reform can limit the increase of the tax burden to $4 \%$ of the value added tax (VAT) rate and the decline in per capita income to less than 6\% in long-run. The key message of the paper is, thus, that a large part of the negative consequences of aging can be offset by a comprehensive reform package to boost the quantity and quality of aggregate labor supply and, thereby, the contribution base of social security.

The paper relates to a large existing literature on aging and social security reform in Switzerland and worldwide. ${ }^{1}$ The demographic effects on the financing of pensions and on the economy are discussed in Miles (1999), BöErsch-Supan and Winter (2001), and Bovenberg and KnAAP (2005), for example. Important survey articles on these topics include Feldstein and Liebman (2002), Bovenberg (2003), Lindbeck and Perrson (2003), and Fenge and Pestieau (2005). WEIL (2006) argues that the most important demographic effects on the economy occur via the financing of pay-as-you-go (PAYG) pensions. A particular problem is the general tendency towards early retirement. Retirement incentives are extensively analyzed in the theoretical and empirical literature, e.g. in GruBER and WISE (1999) who summarize results for a wide range of industrial countries. JAAG et al. (2010), Grafenhofer et al. (2007) and Keuschnigg and Keuschnigg (2004) analyze aging and pension reform in Austria. Lieb et al. (2003) and Abrahamsen and Hartwig (2003) study the expected demographic effects on old-age insurance in Switzerland. Recently, the debate in the U.S. has focussed on either assigning a more important role to capital funding (KотLIKofF, 1997; Feldstein, 2005a,b; Feldstein and SAmwick, 2002) or reforming the existing PAYG system (Diamond, 2004; Diamond and Orszag, 2005).

1 The empirical literature on the labor market impact of taxes and social security is surveyed in Section 3.1. 
We claim that our analysis is one of the most detailed in assessing the potential labor market consequences of aging and social security reform. Most of the literature does not institutionally model the coexistence of PAYG and capital funded pillars and limits attention to only one or two margins of labor supply. We believe, and quantitatively demonstrate, that indeed all five employment margins in our model are important determinants of the economic response to aging and pension reform. A further, novel contribution of the paper is the rigorous analysis of the differential labor market consequences of the PAYG and funded pension system in a unified framework. Agents separately contribute to the PAYG and funded pillars and accumulate private savings to provide for old age consumption. Retirement income stems from private savings on top of separate PAYG and funded pensions. We explicitly show how the three pillars of the Swiss pension system together with labor taxation, unemployment insurance and social assistance add to the effective tax rates on labor supply. To compute these effective tax rates is in itself a novel contribution of the paper.

The paper proceeds as follows. Section 2 presents the model. Section 3 reviews existing empirical evidence on labor market behavior and model calibration. Section 4 presents quantitative results and Section 5 concludes.

\section{A Model of Aging and the Labor Market}

We use a dynamic general equilibrium model with overlapping generations, a rich institutional modeling of the public sector and social security, and five margins of employment $L^{D}$. For the sake of transparency, we present the main identities and behavioral equations to intuitively explain the key transmission channels for policy effects. A complete documentation is found in KeuschnigG and Keuschnigg (2010), referred to as a 'Technical Appendix'. Maybe the most important channel for labor market effects is endogenous retirement which determines the physical labor force $N^{W}$ via a participation decision of older persons. Prime age workers respond on four additional margins: A participation decision determining the participation rate $\bar{\delta}$ where the bar stands for an average among age groups; job search which, together with job creation by firms, results in an unemployment rate $\bar{u}$ of the active labor force; hours worked or effort on the job of employed workers, $\bar{l}$; and life-time training affecting the skill level $\bar{\theta}$,

$$
L_{t}^{D}=\bar{\theta}_{t} \bar{l}_{t}\left(1-\bar{u}_{t}\right) \bar{\delta}_{t} N_{t}^{W}
$$




\subsection{Demographic Change}

We apply an overlapping generations model with a period length of one year. We assume a limited number of age states, $\mathrm{a} \in\{1, \ldots, A\}$, each associated with lifecycle characteristics such as earnings, employment risk and mortality etc. In the calibrated version, we distinguish five active and three retired groups with size $N_{t}^{a}$ as in Table 2 below. ${ }^{2}$ At each date, an individual faces three possible events: (i) she dies with probability $1-\gamma^{a}$; (ii) she survives without aging, i.e. keeps all life-cycle characteristics, and remains in the same age state with probability $\gamma^{a} \omega^{a}$; and (iii) she survives, ages and belongs to group $a+1$ next period with probability $\gamma^{a}\left(1-\omega^{a}\right)$. Individuals in the last state have exhausted the aging process, implying $\omega^{A}=1$ as an end condition. They may either survive with probability $\gamma^{A}$ or die with probability $1-\gamma^{A}$, as in BLANCHARD's (1985) model of perpetual youth. After aggregation, the demographic system is

$$
\begin{aligned}
& N_{t+1}^{a}=\gamma^{a} \omega^{a} N_{t}^{a}+\gamma^{a-1}\left(1-\omega^{a-1}\right) N_{t}^{a-1}, \\
& N_{t+1}^{1}=\gamma^{1} \omega^{1} N_{t}^{1}+n_{t+1}^{0}, \\
& N_{t+1}=N_{t}+n_{t+1}^{0}-\sum_{a \leq A}\left(1-\gamma^{a}\right) N_{t}^{a} .
\end{aligned}
$$

Demographic structure is driven by survival rates $\gamma^{a}$ and $\omega^{a}$, where $1-\gamma^{a}$ is the mortality rate in state $a$ and $1-\omega^{a}$ is the instantaneous probability of moving to the next state. In a demographic steady state, inflows and outflows must balance in each group, $\left(1-\gamma^{a} \omega^{a}\right) N^{a}=\gamma^{a-1}\left(1-\omega^{a-1}\right) N^{a-1}$. The population $N$ remains stationary when the inflow of newborns $n^{0}$ equals the outflow due to mortality, $\Sigma_{a \leq A}\left(1-\gamma^{a}\right) N^{a}$. Demographic change starts when a shock to fertility changes the inflow $n^{0}$, or when improved health raises survival rates $\gamma^{a}$ so that a larger fraction of young groups survive up to old age, resulting in a larger dependency ratio.

Retirement choice occurs in an intermediate state, corresponding to people aged 60 to 69 years old. Retirement is a discrete participation choice in this group, leading to an endogenous fraction $x^{m}$ of still active workers while a share $1-x^{m}$ is retired and collects pension benefits. Use shares $x^{a}=1$ for prime age workers $(a<m), 0<x^{m}<1$ for the mixed and $x^{a}=0$ for fully retired groups $(a>m)$ to

2 People differ by the length of time spent in each state. We thus introduce an index $\alpha$ describing a person's history of aging events, i.e. transition dates across states, leading to a smallest group $N_{\alpha, t}^{a}$ of identical agents. Aggregation of agents in the same state leads to $N_{t}^{a}=\Sigma_{a} N_{\alpha, t}^{a}$. We suppress $\alpha$ in most of what follows, see the Technical Appendix on aggregation. 
divide the population into active and retired persons. The physical labor force $N^{W}$ as stated in (1) and the number of retirees $N^{R}$ are

$$
\begin{aligned}
& N^{W}=\sum_{a=1}^{m} x^{a} N^{a}, \\
& N^{R}=\sum_{a=m}^{A}\left(1-x^{a}\right) N^{a}, \\
& N=N^{W}+N^{R}=\sum_{a} N^{a} .
\end{aligned}
$$

The economic dependency ratio $N^{R} / N^{W}$ depends on retirement choice.

\subsection{Life-Cycle Labor Supply and Consumption}

\subsubsection{Individual Budgets}

Prime age workers in state $a$ are equipped with skill units of labor $\theta^{a}$ so that work per unit of time pays a gross wage $w^{a} \theta^{a}{ }^{3}$ Endogenous training determines lifecycle earnings profiles. Active agents can be in three different labor market states: non-participating; participating and unemployed; and participating and working. Denoting the participation rate by $\delta^{a}$ and the unemployment rate among participating workers by $u^{a}$, average wage related income per unit of skill amounts to

$$
\begin{aligned}
& \bar{y}_{t}^{a}=\delta_{t}^{a} y_{t}^{a}+\left(1-\delta_{t}^{a}\right) s_{t}^{a}, \\
& y_{t}^{a}=\left(1-u_{t}^{a}\right) l_{t}^{a} w_{t}^{n, a}+u_{t}^{a} b_{t}^{a} .
\end{aligned}
$$

When non-participating, agents obtain social assistance and other benefits equal to $s^{a}$. If participating but unemployed, they are entitled to unemployment benefits $b^{a}=b^{U} l^{a} w^{n, a}$ which are indexed to net wage earnings with a replacement rate $b^{U}$. The net wage is reduced by employee contribution rates $t^{E}$ and $t^{F}$ to the PAYG and funded pillars, and by wage tax rates $t^{w, a}$. While contributions are proportional, the wage tax is progressive and implies varying tax rates over the life-cycle, reflecting the typical hump-shaped pattern of life-cycle earnings.

3 Stocks such as skills $\theta_{\alpha, t}^{a}$ also depend on a person's life-cycle history indexed by $\alpha$.We suppress index $\alpha$. 
Since social security contributions are tax deductible, net wages amount to $w^{n, a}=\left(1-t^{w, a}\right)\left(1-t^{E}-t^{F}\right) w^{a}$.

Participation incentives reflect the income gap between replacement income $s^{a}$ and expected income $y^{a}$ when joining the labor force. If participating, an agent finds employment with probability $1-u^{a}$ and earns net wages while she ends up unemployed with probability $u^{a}$ and collects benefits. The employment probability itself is determined by individual incentives for job search which are often substantially undermined by the welfare system. The unemployment rate $u^{a}=1-\zeta^{a} f$ in life-cycle group $a$ depends on individual search effort $\zeta^{a}$ and on the state of the market given by the matching probability $f$ (see Subsection 2.3). High taxes and benefits reduce the income gap between work and unemployment, discourage job search $\zeta^{a}$ and result in a larger unemployment rate. Higher unemployment reduces expected income $y^{a}$ and feeds back negatively on labor market participation. In reality, the transition from one labor market state into another results from a dynamic process with variable job tenure and unemployment spells. This process translates into a cross-section of agents in different labor market states as it is explained by our static search model.

We distinguish four ways to provide for the future: (i) private savings and asset accumulation $A^{a}$; (ii) contributions to the earnings linked pension system, accumulating (implicit) future pension claims $A^{E, a}$; (iii) contributions to the funded pension pillar, accumulating financial assets $A^{F, a}$ in an individual account; and (iv) accumulation of skills by devoting time to training. Individual skills become obsolete with an exogenous rate $1-\delta^{h}$. Agents must thus engage in training to prevent a depreciation of skills. New skills are acquired with a linear homogeneous technology $F\left(E^{a}, I^{a}\right)$ with educational infrastructure and teaching resources $I^{a}$ and effective training $E^{a}$ as inputs. When people are employed, they allocate time to training $e^{a}$ and hours of work $l^{a}$, adding up to $L^{a}=e^{a}+l^{a}$. Since training is on the job, the effective training input is $E^{a}=e^{a}\left(1-u^{a}\right) \delta^{a}$ and rises with higher participation and employment rates. In contrast, non-participation and unemployment lead to a loss of skills. The last equation below captures skill accumulation over the life-cycle,

$$
\begin{aligned}
\gamma^{a} G A_{t+1}^{a} & =R_{t+1}\left[A_{t}^{a}+\bar{y}_{t}^{a} \theta_{t}^{a}+z_{t}^{a}-\left(1+t_{t}^{c}\right) C_{t}^{a}\right], \\
\gamma^{a} G A_{t+1}^{F, a} & =R_{t+1}^{F}\left(A_{t}^{F, a}+T_{t}^{F, a}\right), \quad T_{t}^{F, a} \equiv\left(t_{t}^{F}+t_{t}^{F, F}\right)\left(1-u_{t}^{a}\right) l_{t}^{a} \delta_{t}^{a} w_{t}^{a} \theta_{t}^{a}, \\
G A_{t+1}^{E, a} & =\left(A_{t}^{E, a}+M_{t}^{a}\right), \quad M_{t}^{a} \equiv m^{a}\left(1-u_{t}^{a}+b^{1} u_{t}^{a}\right) l_{t}^{a} \delta_{t}^{a} w_{t}^{a} \theta_{t}^{a}, \\
G \theta_{t+1}^{a} & =F\left(E_{t}^{a}, I_{t}^{a}\right) \theta_{t}^{a}+\delta^{b} \theta_{t}^{a} .
\end{aligned}
$$


The factor $G$ is one plus the growth rate and reflects exogenous productivity growth while $\gamma^{a}$ enters by the assumption of reverse life-insurance as in Blanchard (1985), applied to each group separately. This assumption is most natural with private pension funds. Suppose an agent has one CHF in her account, giving wealth $R_{t+1}^{F}$ next period if she survives. When she dies, her savings are kept by the pension fund. In exchange, she is entitled to a transfer $\tilde{z}^{a}$ which is paid from left-over assets from the deceased. The pension fund breaks even by setting $\gamma^{a} \tilde{z}^{a}=\left(1-\gamma^{a}\right) 1$. Using this, the surviving agent's wealth is $R_{t+1}^{F}\left(1+\tilde{z}^{a}\right)=R_{t+1}^{F} / \gamma^{a}$. When accidental bequests are distributed among surviving agents via this implicit insurance contract, the individuals' effective return on savings is augmented by the factor $1 / \gamma^{a}$. We treat accidental bequests from private savings in the same way, leading to the first equation above where new savings consist of average earnings $\bar{y}^{a} \theta^{a}$ plus fiscal transfers $z^{a}$, minus consumption spending $\left(1+t^{c}\right) C^{a}$ including tax at rate $t^{c}$. In a small open economy, the interest factor $R=1+r$ is fixed on world markets.

The second equation shows the accumulation of financial assets $A^{F, a}$ in the individual account of the mandatory funded pillar. In any period, contributions by workers and firms at rates $t^{F}$ and $t^{F, F}$, respectively, add to existing assets and build up a person's financial wealth until retirement when it is converted into a pension annuity, see subsection 2.2.4 below. The contribution rates apply to gross wage earnings of employed workers, $\left(1-u^{a}\right) l^{a} \delta^{a} w^{a} \theta^{a}$. Unemployment and nonparticipation result in lower contributions and reduce pensions after retirement. We assume that the funded system generates a return on assets possibly below the market return, $R^{F} \leq R$. The return differential captures costly investment regulations and high administrative costs, making savings via the funded system only an imperfect substitute for private savings.

The third equation models the accumulation of implicit pension claims $A^{E, a}$ in the earnings linked PAYG pillar. At any date, new pension claims are added which are equal to the fraction $m^{a}$ of the pension assessment base which normally would consist of earnings of an employed worker, equal to $\left(1-u^{a}\right) l^{a} \delta^{a} w^{a} \theta^{a}$ on average. In Switzerland, unemployment benefits received during periods of joblessness fully raise the assessment base. ${ }^{4}$ Hence, the coefficient $b^{1}$ is equal to the gross replacement rate. Other countries often apply similar rules. The factor $m^{a}$ captures the tax benefit link in the PAYG system. If it were zero, future benefits would be independent of current earnings, making the contribution rate a full labor tax. If it is positive, agents anticipate that higher earnings today will

4 In the funded pillar, in contrast, benefits only depend on actual contributions paid. 
translate into higher benefits in the retirement period, so that contributions are perceived less as a tax. At the date of retirement, the starting pension is equal to accumulated claims.

\subsubsection{Consumption}

Anticipating consequences later in life, agents optimally choose consumption and work related activities to maximize expected life-time utility $V_{t}^{a} \equiv V\left(A_{t}^{a}, A_{t}^{E, a}, A_{t}^{F, a}, \theta_{t}^{a}\right)$. Preferences in recursive form (see FARMER, 1990; WEIL, 1990; and Gertler, 1999) are

$$
V_{t}^{a}=\max _{C_{t}^{a}, l_{t}^{a}, e_{t}^{a}, \zeta_{t}^{,}, \delta_{t}^{a}, x_{t}^{m}}\left[\left(C_{t}^{a}-\bar{\varphi}_{t}^{a} \theta_{t}^{a}\right)^{\rho}+\gamma^{a} \beta\left(G \bar{V}_{t+1}^{a}\right)^{\rho}\right]^{1 / \rho},
$$

where $\beta$ is a subjective discount factor and $\sigma=1 /(1-\rho)$ is the intertemporal elasticity of substitution. Expected utility next period, $\bar{V}_{t+1}^{a}=\omega^{a} V_{t+1}^{a}+\left(1-\omega^{a}\right) V_{t+1}^{a+1}$ takes account of the fact that, with probability $1-\omega^{a}$, the agent may switch to the next age state $a+1$. Instantaneous utility $Q_{t}^{a} \equiv C_{t}^{a}-\bar{\varphi}_{t}^{a} \theta_{t}^{a}$ is assumed separable in consumption $C_{t}^{a}$ and employment related effort cost $\bar{\varphi}_{t}^{a}$. Separability avoids income effects on labor supply. Total effort cost is

$$
\begin{aligned}
\bar{\varphi}_{t}^{a}= & \delta_{t}^{a}\left[\left(1-u_{t}^{a}\right) \varphi_{L}\left(l_{t}^{a}+e_{t}^{a}\right)-u_{t}^{a} h^{p, a}+\varphi_{S}\left(\zeta_{t}^{a}\right)\right] \\
& -\left(1-\delta_{t}^{a}\right) h^{n p, a}+\varphi_{P}\left(\delta_{t}^{a}\right),
\end{aligned}
$$

where $\varphi_{L}\left(l_{t}^{a}+e_{t}^{a}\right), \varphi_{S}\left(\zeta_{t}^{a}\right)$ and $\varphi_{P}\left(\delta_{t}^{a}\right)$ are convex increasing cost functions. In any given period, workers pursue a sequence of activities: (i) At the beginning of period, they decide on labor market participation which causes a fixed cost or disutility $\varphi_{P}\left(\delta^{a}\right)$. With probability $1-\delta^{a}$, they remain inactive and derive utility $h^{n p, a}$ from home production. With probability $\delta^{a}$, they become part of the active workforce. (ii) If participating, workers incur an effort cost $\varphi_{S}\left(\zeta^{a}\right)$ and search with intensity $\zeta^{a}$ which results in a job with probability $1-u^{a}$ or in unemployment with probability $u^{a}$. When unemployed, agents enjoy home production or leisure equal to $h^{p, a}$. (iii) If employed, workers supply a total amount of time $l^{a}+e^{a}$ to work and training, resulting in effort cost $\varphi_{L}\left(l^{a}+e^{a}\right)$. Summing up, an agent is, a priori, employed with probability $\left(1-u^{a}\right) \delta^{a}$, unemployed with probability $u^{a} \delta^{a}$, and non-participating with probability $1-\delta^{a}$.

Given four alternative ways to provide for future consumption, four margins of labor market activity of prime age workers, and a multitude of policy instruments, 
the solution of the household sector is necessarily complicated (see the Technical Appendix for details). However, household sector behavior reflects the same economic intuition known from more stylized models. For example, an Euler equation of desired consumption growth implies consumption smoothing and leads to total consumption net of effort costs equal to

$$
\left(1+t_{t}^{c}\right) Q_{t}^{a}=\left(\Delta_{t}^{a}\right)^{-1}\left(A_{t}^{a}+H_{t}^{a}+S_{t}^{E, a}+S_{t}^{F, a}+T_{t}^{a}\right) .
$$

Spending on total consumption is a fraction of life-time wealth, consisting of financial assets $A^{a}$, human wealth $H^{a}$, social security wealth from PAYG and funded pensions, $S^{E, a}$ and $S^{F, a}$, respectively, and a present value of other transfers $T^{a}$ including the value of lump-sum pensions. The marginal propensity to consume is $1 / \Delta^{a}$ as listed in Table 2 below and rises with higher mortality rates in later stages of life. It is governed by the forward looking system

$$
\Delta_{t}^{a}=1+\gamma^{a} \beta^{\sigma}\left[\frac{1+t_{t}^{c}}{1+t_{t+1}^{c}} R_{t+1} \Omega_{t+1}^{a}\right]^{\sigma-1} \Delta_{t+1}^{a}
$$

where

$$
\Omega_{t+1}^{a}=\omega^{a}+\left(1-\omega^{a}\right)\left[\frac{\Delta_{t+1}^{a+1}}{\Delta_{t+1}^{a}}\right]^{\frac{1-\rho}{\rho}}
$$

is a magnification of the interest factor reflecting substitution across life-cycle states. In other words, agents discount the future at a higher rate when mortality rises.

\subsubsection{Prime Age Labor Market Activity}

To study the effects of tax and pension reform on employment, we calculate implicit contribution taxes. Taking derivatives of the value function in (6) yields shadow prices of the state variables,

$$
\eta^{a}=\frac{d V^{a}}{d A^{a}}, \chi^{a}=\frac{\frac{d V^{a}}{d \theta^{a}}}{\frac{d V^{a}}{d A^{a}}} \text { and } \lambda^{j, a}=\frac{\frac{d V^{a}}{d A^{j, a}}}{\frac{d V^{a}}{d A^{a}}} .
$$


For example, the shadow price $\lambda^{E, a}$ stands for the value of additional future pension claims in the PAYG pillar if $d A^{E, a}$ units are added to the pension assessment base of an agent in state $a$ at date $t$. This marginal value reflects the increase in life-time utility as measured in units of financial wealth. Similarly, $\lambda^{F, a}$ is an agent's valuation of an extra CHF in the individual account of the funded pillar. Next period, the individual may still be in the same age state or move to the next one, implying an expected value $\bar{\lambda}_{t+1}^{j, a} \equiv \omega^{a} \lambda_{t+1}^{a}+\left(1-\omega^{a}\right) \lambda_{t+1}^{j, a+1}$. Further, as mentioned subsequent to equation (8), the term $\Omega_{t+1}^{a}$ magnifies the discount factor to reflect mortality. With these definitions, the Technical Appendix calculates the following effective or implicit tax rates,

$$
\begin{aligned}
& \hat{t}_{t}^{w, a} \equiv\left[t_{t}^{w, a}-b^{U} \frac{u_{t}^{a}}{1-u_{t}^{a}}\left(1-t_{t}^{w, a}\right)\right]\left(1-t_{t}^{E, a}-t_{t}^{F, a}\right), \\
& \hat{t}_{t}^{E, a} \equiv t_{t}^{E}-\bar{s}_{t}^{E, a}, \quad \bar{s}_{t}^{E, a} \equiv m^{a}\left[1+b^{1} \frac{u_{t}^{a}}{1-u_{t}^{a}}\right] \gamma^{a} \frac{\bar{\lambda}_{t+1}^{E, a}}{R_{t+1} \Omega_{t+1}^{a}}, \\
& \hat{t}_{t}^{F, a} \equiv t_{t}^{F}-\bar{s}_{t}^{F, a}, \quad \bar{s}_{t}^{F, a} \equiv\left(t_{t}^{F}+t_{t}^{F, F}\right) R_{t+1}^{F} \frac{\bar{\lambda}_{t+1}^{F, a}}{R_{t+1} \Omega_{t+1}^{a}} .
\end{aligned}
$$

Intensive Labor Supply: Earnings of an employed worker are subject to an effective wage $\operatorname{tax} \hat{t}^{w, a}$. This tax rate is reduced by the deductibility of social security contributions, yielding the term $\left(1-t^{E}-t^{F}\right) t^{w, a}$. It is further reduced by wage indexation of unemployment benefits at rate $b^{U}$. When employed, working more hours not only raises earnings but also raises benefits at rate $b^{U}$, should the worker become unemployed, where $u^{a} /\left(1-u^{a}\right)$ is the conditional probability of this event. Hence, benefit indexation in unemployment insurance further reduces the effective wage tax and strengthens work incentives, as given by the optimality condition

$$
\varphi_{L}^{\prime}\left(L_{t}^{a}\right)=\frac{1-\tau_{t}^{L, a}}{1+t_{t}^{c}} w_{t}^{a}, \tau_{t}^{L, a} \equiv \hat{t}_{t}^{w, a}+\hat{t}_{t}^{E, a}+\hat{t}_{t}^{F, a} .
$$

Labor supply is also discouraged by effective contribution taxes in (9). The implicit tax $\hat{t}^{E, a}$ of the earnings linked pension system is much reduced if there is an effective tax benefit link $m^{a}$. Higher earnings today add to the assessment base and raise benefits after retirement. The present value is equal to $\bar{s}^{E, a}$ and reduces the tax character of the statutory contribution rate. Strengthening the 
tax benefit link thereby boosts intensive labor supply. The effective tax is further reduced when the system allows unemployment spells to result in additional pension claims, $b^{1}>0$. In this case, unemployment creates additional future pension benefits because a fraction $b^{1}$ of 'last earnings' is added to the assessment base. However, the same rule creates an additional benefit of remaining unemployed and weakens search effort, as will be seen below.

Finally, the effective contribution tax $\hat{t}^{F, a}$ to the funded pension system is very low, and is zero under ideal conditions. When an individual pays into her individual account at the statutory rate $t^{F}$, the contribution will earn an interest and grow with factor $R^{F}$, much like private savings. At the date of retirement, the individual gets a pension annuity with a present value equal to accumulated assets in the account. All this would just replicate private savings if $R^{F}=R$. If there are no other differences in savings via the pension account or private savings, the contribution would not at all be perceived as a tax, giving an effective tax rate of zero. If $R^{F}<R$, savings via the pension account yields a lower return and contains a tax component which is detrimental to work effort. On the other hand, the effective tax is reduced to the extent that firms contribute at rate $t^{F, F}$, thereby subsidizing worker contributions. The firm's contribution rate is a full factor tax discouraging employment by firms, but stimulates work effort of employees. The net effect may be largely neutral.

Training: When employed, agents allocate time $l^{a}+e^{a}$ on training and work. Training is optimal when the marginal return is equal to its opportunity cost,

$$
\frac{1-\tau_{t}^{L, a}}{1+t_{t}^{c}} w_{t}^{a}=\varphi_{L}^{\prime}\left(l_{t}^{a}+e_{t}^{a}\right)=\frac{F_{E}^{a}\left(E_{t}^{a}, I_{t}^{a}\right)}{1+t_{t}^{c}} \frac{\gamma^{a} \bar{\chi}_{t+1}^{a}}{R_{t+1} \Omega_{t+1}^{a}} .
$$

A unit of training raises individual skills by $F_{E}^{a}=d F^{a} / d E^{a}$, where $E^{a}=e^{a}\left(1-u^{a}\right) \delta^{a}$, i.e. training is conditional on being employed. The skill improvement shifts up future earnings and boosts human capital by $\gamma^{a} \bar{\chi}_{t+1}^{a} /\left(R_{t+1} \Omega_{t+1}^{a}\right)$. Postponed retirement means that the additional earnings from training accrue over a longer working life and boosts training incentives. The effect should be more important for persons close to retirement where an increase in retirement age means a disproportionately large extension of the remaining working life.

Job Search: Given participation, a person's probability of employment is $1-u^{a}=\zeta^{a} f$ and depends on individual search intensity $\zeta^{a}$ and the matching rate $f$. The matching rate reflects equilibrium market tightness and is individually taken as given. Devoting more effort to job search marginally raises a person's 
employment probability by $f$. Clearly, the gains to search consist of the increase in life-time welfare when an individual switches from unemployment into a job. Equating this to the marginal effort cost yields the optimality condition

$$
\begin{aligned}
\varphi_{S}^{\prime}\left(\zeta_{t}^{a}\right) & =f_{t}\left[\frac{1-\tau_{t}^{S, a}}{1+t_{t}^{c}} w_{t}^{a} l_{t}^{a}+e_{t}^{a} F_{E}^{a} \frac{\gamma^{a} \bar{\chi}_{t+1}^{a}}{R_{t+1} \Omega_{t+1}^{a}}-\varphi_{L}^{a}-b^{p, a}\right] \\
\tau_{t}^{S, a} & \equiv\left(1-t_{t}^{E}-t_{t}^{F}\right) t_{t}^{w, a}+\frac{b_{t}^{a}}{w_{t}^{a} l_{t}^{a}}+t_{t}^{c} \frac{e_{t}^{a} F_{E}^{a}}{w_{t}^{a} l_{t}^{a}} \frac{\gamma^{a} \bar{\chi}_{t+1}^{a}}{R_{t+1} \Omega_{t+1}^{a}} \\
& +\left(t_{t}^{F, a}-\bar{s}_{t}^{F, a}\right)+\left[t_{t}^{E}-m^{a}\left(1-b^{1}\right) \frac{\gamma^{a} \bar{\lambda}_{t+1}^{a}}{R_{t+1} \Omega_{t+1}^{a}}\right]
\end{aligned}
$$

Consider first a situation without government. When finding a job, a person spends $l^{a}$ hours working, earns $w^{a} l^{a}$, and devotes $e^{a}$ hours to training, yielding higher future earnings equal to $F_{E}^{a} \gamma^{a} \bar{\chi}_{t+1}^{a} /\left(R_{t+1} \Omega_{t+1}^{a}\right)$ in present value. When accepting a job offer, a person must also incur an effort $\cos t \varphi_{L}^{a}$ of work and training and, in addition, must give up the utility value of home production $h^{p, a}$ during unemployment. Both costs subtract from job surplus. Optimal search equates marginal cost with the expected surplus, $\varphi_{S}^{\prime}\left(\zeta_{t}^{a}\right)=f_{t} \times[\cdot]$.

The effective tax rate $\tau^{S, a}$, together with the consumption tax, summarizes the total influence of the fiscal system on search incentives. This effective tax rate is itself a novel measure of the combined labor market impact of tax and social security. The first two terms correspond to the standard notion of a participation tax rate in the sense of IMMERVOLL et al. (2007) which is the sum of the wage tax (reduced by the deductibility of social security contributions) and the replacement rate in unemployment insurance, $b^{a} /\left(w^{a} l^{a}\right)$. When a person switches from unemployment into a job, she incurs a double cost, namely paying wage tax and giving up unemployment benefits. Given average tax rates and a replacement rate around $50 \%$, the effective tax rate is rather substantial. The consumption tax erodes real wages as well and discourages job search. It not only deflates current earnings and thereby enters in the denominator of (12), but also erodes future earnings due to training, leading to the third term in $\tau^{S, a}$.

The fourth term shows how search incentives are undermined by the effective contribution tax $\hat{t}^{F, a}=t_{t}^{F}-\bar{s}_{t}^{F, a}$ for funded pensions. The last term captures the impact of the PAYG pillar. If the system would deny unemployment benefits to count towards the assessment base $\left(b^{1}=0\right)$, the effect on search incentives would 
be given by the effective rate $\hat{t}^{E, a}=t_{t}^{E}-\bar{s}_{t}^{E, a}$ as well. This tax rate is surely higher than the one for funded pensions since contributions to the PAYG system do not earn interest. More importantly, Switzerland (as do other countries) allows periods of unemployment to add to pension claims, by crediting a part $b^{1}$ of last earnings towards the assessment base. This means that pension claims are not only created by actual contributions when employed, but also when unemployed. Hence, the rule weakens the negative consequences of unemployment for future pension income and, hence, undermines search incentives. In the extreme case $\left(b^{1} \rightarrow 1\right)$, the rule reduces the last term to $t^{E}$, meaning that the contribution rate $t^{E}$ becomes a full tax on job search. In reality, the parameter $b^{1}$ is equal to the gross replacement rate in unemployment insurance. By allowing unemployment benefits to add to the assessment base, the system substantially raises the effective tax and discourages job search. ${ }^{5}$

Labor Market Participation: When more households plan to join the active labor force, the participation rate $\delta^{a}$ rises. The condition for optimal participation is

$$
\begin{aligned}
\varphi_{P}^{\prime}\left(\delta_{t}^{a}\right) & =\frac{1-\tau_{t}^{P, a}}{1+t_{t}^{c}}\left(1-u_{t}^{a}\right) w_{t}^{a} l_{t}^{a}+\left(1-u_{t}^{a}\right) e_{t}^{a} F_{E}^{a} \frac{\gamma^{a} \bar{\chi}_{t+1}^{a}}{R_{t+1} \Omega_{t+1}^{a}}-\Psi_{t}^{a}, \\
\tau_{t}^{P, a} & \equiv \hat{t}_{t}^{w, a}+\hat{t}_{t}^{E, a}+\hat{t}_{t}^{F, a}+\frac{s_{t}^{a}}{\left(1-u_{t}^{a}\right) w_{t}^{a} l_{t}^{a}}+t_{t}^{c} \frac{e_{t}^{a} F_{E}^{a}}{w_{t}^{a} l_{t}^{a}} \frac{\gamma^{a} \bar{\chi}_{t+1}^{a}}{R_{t+1} \Omega_{t+1}^{a}} .
\end{aligned}
$$

When people decide to participate and start searching for employment, they will either find a job or end up unemployed. In the absence of government, they expect to be employed with probability $1-u^{a}$, in which case they earn current income from $l^{a}$ hours of work. Allocating $e^{a}$ units of time to training adds future income equal to $F_{E}^{a} \bar{\chi}_{t+1}^{a} /\left(R_{t+1} \Omega_{t+1}^{a}\right)$ in present value. These gains are partly offset by the utility $\operatorname{cost}^{6} \Psi^{a} \equiv h^{n p, a}+\varphi_{S}^{a}+\left(1-u^{a}\right) \varphi_{L}^{a}-u^{a} b^{p, a}$ which consists of (i) the foregone utility from household production $b^{n p, a}$ of a non-participating person; (ii) the effort cost $\varphi_{S}^{a}$ of job search; (iii) the effort cost $\left(1-u^{a}\right) \varphi_{L}^{a}$ of training and work when the agent finds a job with probability $1-u^{a}$, and (iv) the reduction $u^{a} b^{p, a}$ in the utility cost of participation by the value of home production when the agent ends up unemployed. By (13), optimal participation equates marginal utility $\operatorname{cost} \varphi_{P}^{\prime}\left(\delta^{a}\right)$ to marginal gains.

5 Note, however, the positive impact of $b^{1}$ on the intensive hours margin as discussed in (10).

6 The derivative of (7) enters the optimality condition by $d \bar{\varphi}^{a} / d \delta^{a}=\varphi_{p}^{\prime}\left(\delta^{a}\right)+\Psi^{a}$. 
The measure $\tau^{P, a}$ summarizes the impact of taxes and social security. In the simplest case without unemployment, training and a pension system, the effective tax simplifies to the sum of the wage tax plus the replacement rate in social assistance, $\tau^{P, a}=t^{w, a}+s^{a} /\left(w^{a} l^{a}\right)$, which is in full parallel to IMMERvol et al. (2007). Adding several other dimensions of labor supply and welfare policy makes this measure more complicated, of course. First, the impact of unemployment insurance is captured by the effective wage tax $\hat{t}^{w, a}$ as defined in (9). Hence, a higher replacement rate $b^{U}$ of wage indexed unemployment insurance reduces the effective tax by lowering $\hat{t}^{w, a}$. Participation is encouraged if unemployment benefits are more generous. Second, participation is discouraged by effective contribution taxes $\hat{t}^{E}$ and $\hat{t}^{F}$. Strengthening the tax benefit link in old age insurance lowers implicit taxes and thereby boosts participation. Finally, the consumption tax discourages participation in much the same way as job search, see (12).

\subsubsection{Retirement}

In an aging society, retirement is arguably the most important channel for aggregate labor supply. ${ }^{7}$ We thus add a retirement decision as another participation decision of older workers. We interpret the participation rate $x \in[0,1]$ as the retirement date since the retirement date in the time span of ages 60 to 69 can be mapped one to one into a participation rate in the cross-section of the population aged 60 to 69 . Approximately, a retirement date of 65 corresponds to a participation rate of .5. In the next group, representing people aged $70+$, the participation rate is zero as all people are retired. Using this approximation, agents in this mixed group work and spend time in retirement where the shares determine average income

$$
Y_{t}^{a}=x_{t} \bar{y}_{t}^{a} \theta_{t}^{a}+\left(1-x_{t}\right)\left(1-t_{t}^{w, a}\right) \sum_{j} P_{t}^{j, a}
$$

A fraction $1-x$ of the 'mixed' group is retired, corresponding to a share of time spent in retirement each period per capita. Agents collect three types of pensions, $j \in\{E, F, L\}$, i.e. earnings linked PAYG, funded and lump-sum pensions. Postponing retirement leads to a net income gain of

7 See Börsch-Supan (2000), Mitchell and Phillips (2000), Crémer and Pestieau (2003), Bütler et al. (2004) and Gruber and Wise (2004), among others. Fisher and Keuschnigg (2010) emphasize how the retirement decision interacts with labor supply incentives earlier in the life-cycle. 


$$
d Y^{a} / d x=\bar{y}^{a} \theta^{a}-\left(1-t_{t}^{w, a}\right) \sum_{j} P^{j, a} .
$$

However, for physical and psychological reasons, individuals find it increasingly burdensome and costly to postpone retirement which is captured by a progressively rising disutility $\varphi_{R}(x), \varphi_{R E}^{\prime}, \varphi_{R}^{\prime \prime}>0$. We thus expand instantaneous utility in (6-7) to $C^{a}-x \bar{\varphi}^{a} \theta^{a}-\varphi_{R}(x)$. With this modification, (6) gives expected life-time utility of an agent in the mixed group over her remaining life-horizon.

Private assets and skills grow as in (5) except that earnings are replaced by $Y^{n}$ as in (14) and the time input into training is scaled down by the rate $x$, $E^{a}=e^{a}\left(1-u^{a}\right) \delta^{a} x$, since agents do not train when retired. The key difference to prime age workers is pension income. In the earnings linked and funded pillar, pensions depend on two factors, (i) accumulated entitlements, and (ii) supplements or discounts for early or late retirement. The transition into partial retirement is modeled as follows. When a prime age worker is in age state $a$ in period $t$ and switches to the 'mixed' age state $a+1$ in period $t+1$, she is endowed with a starting pension equal to

$$
P_{t+1}^{F, a+1}=\frac{A_{t+1}^{F, a}}{\mu_{t+1}^{F, a+1}}, \quad P_{t+1}^{E, a+1}=A_{t+1}^{E, a}, \quad P_{t+1}^{L, a+1}=P_{t+1}^{L, 0}
$$

In the first equation, $\mu_{t+1}^{F, a+1}$ is an annuity price equal to the present value of a stream of income that starts with $1 \mathrm{CHF}$ in period $t+1$ and grows by the indexation factor $G^{P}$ each year thereafter, plus some additions when the participation rate is larger than zero, reflecting a reward for late retirement (see below). ${ }^{8}$ The condition $P_{t+1}^{F, a+1} \mu_{t+1}^{F, a+1}=A_{t+1}^{F, a}$ imposes intertemporal budget balance of the individual account. Starting the mixed age state in period $t+1$, the individual gets a starting pension $P_{t+1}^{E, a+1}$ from the PAYG pillar which is equal to previously acquired pension entitlements $A_{t+1}^{E, a}$ on past earnings, see (5). Finally, the starting level $P_{t+1}^{L, 0}$ of the lump-sum pension is a policy variable. This flat pension is not linked to past earnings and contributions. In part, it reflects social policy to prevent old age poverty among low income persons. It also captures the fact that

8 Similar to private agents, the pension fund also discounts future obligations with the effective interest factor $R_{t+1}^{F} \Omega_{t+1}^{a}$ where the factor $\Omega_{t+1}^{a}$ magnifies discounting to reflect the probability that, at any date, mortality terminates pension obligations:

$$
\mu_{t}^{F, a}=1-x_{t}^{a}+\left(\gamma^{a} G^{P}+\phi_{t}^{a} R_{t+1}^{F}\right) \bar{\mu}_{t+1}^{F, a} /\left(\Omega_{t+1}^{a} R_{t+1}^{F}\right) .
$$


earnings in excess of an income ceiling do not create pension entitlements anymore. Hence, the tax benefit link is also cut for a share of people with incomes in excess of the ceiling, making their contributions a full tax.

Conditional on chosen retirement age, individuals get pension supplements or discounts so that actual pensions after entry into the mixed state are assumed to follow

$$
\begin{aligned}
& G P_{t+1}^{F, a}=G^{P} P_{t}^{F, a}+\sigma^{F}\left(x_{t}\right)\left(T_{t}^{F, a}+P_{t}^{F, a}\right) R_{t+1}^{F} / \gamma^{a}, \\
& G P_{t+1}^{E, a}=G^{P} P_{t}^{E, a}+\sigma^{E}\left(x_{t}\right)\left(M_{t}^{a}+P_{t}^{E, a}\right), \\
& G P_{t+1}^{L, a}=G^{P} P_{t}^{L, a},
\end{aligned}
$$

where $T^{F, a}$ are contributions to the pension fund by employees at rate $t^{F}$ and employers at rate $t^{F, F}$, and $M^{a}$ are new entitlements created in the earnings linked system, see (5). If $G^{P}=G$, then pensions grow at the exogenous rate of productivity growth. If $G^{P}=1$, pension growth is linked to the price level only, leading to constant pensions in our model with constant goods prices (normalized to one). The $\sigma^{j}$-functions reward postponed retirement according to

$$
\sigma^{F}\left(x_{t}\right)=x_{t} \frac{\Omega_{t+1}^{a}}{\bar{\mu}_{t+1}^{F, a}}, \quad \sigma^{E}\left(x_{t}\right)=\left(x_{t}-x^{R}\right) \sigma_{1}+\sigma_{0}^{E} .
$$

The pension fund rewards postponed retirement in a forward looking way where the factor $\sigma^{F}$ is chosen to satisfy the intertemporal budget constraint. Therefore, the statutory retirement date (normal participation rate) $x^{R}$ does not play a particular role. If the individual chooses a retirement date $x>0$, she pays contributions and saves pension outlays. This gross saving in the pension account is also converted with effective interest $R_{t+1}^{F} / \gamma^{a}$, much the same way as in (15), into a pension addition next period of

$$
\left(T_{t}^{F, a}+P_{t}^{F, a}\right) \frac{R_{t+1}^{F}}{\gamma^{a}} \frac{x_{t} \Omega_{t+1}^{a}}{\bar{\mu}_{t+1}^{F, a}} .
$$

Our notion of actuarial fairness means that these operations must satisfy the intertemporal constraint on the individual account. The PAYG pillar can also make the pension conversion rate sensitive to the retirement date. If people retire at the statutory age $x=x^{R}$, the solution of (16) yields a normal PAYG pension. If the system offers retirement incentives along the lines of GRUBER and WISE 
(1999), late retirement by choosing $x>x^{R}$ raises the factor $\sigma^{E}$ and results in a larger pension, and conversely for early retirement.

The value function becomes $V\left(A_{t}^{a}, P_{t}^{E, a}, P_{t}^{F, a}, P_{t}^{L, a}, \theta_{t}^{a}\right)$ since state variables change from $A_{t}^{E, a}$ to $P_{t}^{E, a}$ etc. when moving to the mixed state. Tedious computations documented in the Technical Appendix yield the condition for optimal retirement and old age participation,

$$
\begin{aligned}
\varphi_{R}^{\prime}\left(x_{t}\right)= & {\left[\frac{1-\tau_{t}^{R}}{1+t_{t}^{c}} l_{t}^{a}\left(1-u_{t}^{a}\right) \delta_{t}^{a} w_{t}^{a}+e_{t}^{a}\left(1-u_{t}^{a}\right) \delta_{t}^{a} F_{E}^{a} \frac{\gamma^{a} \bar{\chi}_{t+1}^{a}}{R_{t+1} \Omega_{t+1}^{a}}-\bar{\varphi}_{t}^{a}\right] \theta_{t}^{a}, } \\
\tau_{t}^{R}= & \hat{t}_{t}^{w, a}-\frac{\left(1-\delta_{t}^{a}\right) s_{t}^{a}}{\left(1-u_{t}^{a}\right) l_{t}^{a} \delta_{t}^{a} w_{t}^{a}}+t_{t}^{c} \frac{e_{t}^{a} F_{E}^{a}}{l_{t}^{a} w_{t}^{a}} \frac{\gamma^{a} \bar{\chi}_{t+1}^{a}}{R_{t+1} \Omega_{t+1}^{a}} \\
& +\left[t_{t}^{E}-\bar{s}_{t}^{E, a} \frac{d \sigma_{t}^{M}}{d x_{t}}+\frac{\left(1-t_{t}^{w, a}\right)\left(P_{t}^{L, a}+P_{t}^{E, a}\right)-\frac{d \sigma_{t}^{p}}{d x_{t}} P_{t}^{E, a} \frac{\gamma^{a} \bar{\lambda}_{t+1}^{F, a}}{R_{t+1} \Omega_{t+1}^{a}}}{\left(1-u_{t}^{a}\right) l_{t}^{a} \delta_{t}^{a} w_{t}^{a} \theta_{t}^{a}}\right] \\
& +\left[t_{t}^{F}-\bar{s}_{t}^{F, a} \frac{d \sigma_{t}^{F}}{d x_{t}}+\frac{\left(1-t_{t}^{w, a}\right) P_{t}^{F, a}-\frac{d \sigma_{t}^{F}}{d x_{t}} P_{t}^{F, a} R_{t+1}^{F} \frac{\bar{\lambda}_{t+1}^{F, a}}{R_{t+1} \Omega_{t+1}^{a}}}{\left(1-u_{t}^{a}\right) l_{t}^{a} \delta_{t}^{a} w_{t}^{a} \theta_{t}^{a}}\right] .
\end{aligned}
$$

A non-retired person may still choose inactivity by living off home production and social assistance at a rate $\delta^{a}$, instead of actively searching for a job. Old workers thus make a nested participation decision. In the absence of a public sector, there is no replacement income whatsoever. Consumption must be entirely prefinanced with private savings. Postponing retirement and remaining active creates income only in the employed state which happens with probability $\left(1-u^{a}\right) \delta^{a}$. In this case, a person works $l^{a}$ hours and earns $w^{a} l^{a}$ per unit of skill, and devotes time $e^{a}$ to training to keep up skills for the remaining work period, adding income $e^{a} F_{E}^{a} \gamma^{a} \bar{\chi}_{t+1}^{a} /\left(R_{t+1} \Omega_{t+1}^{a}\right)$ in present value. However, an individual also incurs total effort cost $\bar{\varphi}^{a}$ as long as she remains active. With optimal retirement, the net gain in life-time income from working an instant longer is just equal to the marginal utility cost of continued participation.

Fiscal retirement incentives, or disincentives for continued work, are summarized by an effective tax rate $\tau^{R}$. For intuition, take first the simplest case with full participation of active workers $\left(\delta^{a}=1\right)$, no unemployment $\left(u^{a}=0\right)$, no training $\left(e^{a}=0, \theta^{a}\right.$ fixed) and no other public program beyond a flat PAYG system with a rate $t^{E}$ and a flat pension $P^{L}$. Retirement choice reduces to $\varphi_{R}^{\prime}(x)=\left[\left(1-\tau^{R}\right) l^{a} w^{a}-\varphi_{L}^{a}\right] \theta^{a}$ which is fully parallel to modeling retirement in 
Crömer and Pestieau (2003), for example. The effective tax is the sum of contribution and pension replacement rates, $\tau^{R}=t^{E, a}+P^{L, a} /\left(l^{a} w^{a} \theta^{a}\right)$ and is, thus, very high. Again, this rate corresponds to a participation tax as in IMMERvolL et al. (2007).

In general, the effective rate $\tau^{R}$ measures the total fiscal burden of remaining active for an additional time unit. The role of the consumption tax is as before. Further, a higher replacement rate $b^{U}$ in unemployment insurance (reducing the effective wage $\operatorname{tax} \hat{t}^{w, a}$ ) and better protection of an active worker with social assistance (larger $s^{a}$ ) encourages prolonged work since it strengthens expected income of staying active. Finally, the last two square brackets capture the influence of the PAYG and funded pension pillars on retirement incentives. Denoting replacement rates by $\bar{p}^{j, a} \equiv P^{j, a} /\left[\left(1-u^{a}\right) l^{a} \delta^{a} w^{a} \theta^{a}\right]$, for the moment, we find that the flat basic pension always discourages retirement by the net replacement ratio $\left(1-t^{w, a}\right) \bar{p}^{L, a}$. The earnings linked PAYG pillar adds a participation $\operatorname{tax} t^{E}+\left(1-t^{w, a}\right) \bar{p}^{E, a}$ as in the simple example above. The tax is greatly reduced, however, if the system includes 'Gruber Wise' incentives $\sigma^{E}(x)$ for late retirement by making pensions sensitive to the chosen retirement date as in (17). The factor $\sigma^{E}$ rises above $\sigma_{0}^{E}$ if an individual postpones retirement beyond the statutory retirement age, which raises pension benefits in (16). The entire benefit stream until the end of life shifts up in proportion to $d \sigma^{E} / d x$, giving a present value of $\gamma^{a} \bar{\lambda}_{t+1}^{E, a} /\left(R_{t+1} \Omega_{t+1}^{a}\right)$ per CHF of the added pension. Early retirement, in contrast, triggers a pension discount which inflates the participation tax and discourages this behavior.

Labor Market Neutrality of Funded Pensions: Funded pensions can raise the old age participation tax in a significant way as well. The interpretation of the last line in (18) is qualitatively identical to the case of the PAYG system, except that retirement incentives are calculated in an actuarially fair way to satisfy the intertemporal constraint in the individual account. Under ideal conditions, the funded pension pillar is fully neutral towards retirement choice and other margins of labor supply. To see this, set all other taxes to zero (which always distort retirement choice) and also set firm contributions to zero so that $\bar{s}_{t}^{F, a} \equiv t_{t}^{F} R_{t+1}^{F} \bar{\lambda}_{t+1}^{F, a} /\left(R_{t+1} \Omega_{t+1}^{a}\right)$ by the definition in (9). If the pension fund is able to offer the market rate of return, $R^{F}=R$, and using the factor $d \sigma^{F} / d x=\Omega_{t+1}^{a} / \bar{\mu}_{t+1}^{F, a}$, the last line in (18) emerges as $\left(t_{t}^{F}+\bar{p}_{t}^{F, a}\right)\left(1-\bar{\lambda}_{t+1}^{F, a} / \bar{\mu}_{t+1}^{F, a}\right)=0$. If the pension fund offers exactly the same

9 See Queisser and Whitehouse (2006) for a discussion of actuarial fairness and neutrality in the design of pension systems. 
interest as is available to private households, than the shadow price of a pension annuity must also be the same for the pension fund and private households, so that $\bar{\lambda}_{t+1}^{F, a}=\bar{\mu}_{t+1}^{F, a}$ (details are shown in the Technical Appendix). In other words, private savings or savings via contributions to the pension fund are perfect substitutes without any implicit tax component. Hence, under ideal conditions, the capital funded system does not distort retirement behavior. KeUsCHNIGG and Keuschnigg (2010) show that, under these conditions, the neutrality extends to other margins of labor supply as well. A deviation from these conditions, however, such as high administration costs leading to $R^{F}<R$ or presence of wage taxes etc. make the capital funded pillar also distortive in a minor way.

\subsection{Production and the Labor Market}

Unemployment results from search frictions in a matching labor market where workers in search for a job meet firms wanting to fill vacancies. Using the notation in (3), we have $x^{a} N^{a}$ active households in age group $a$, who participate at rate $\delta^{a}$ and spend time $\zeta^{a}$ per person on job search. These activities add up to a total supply of $L^{M}=\Sigma_{a} \zeta^{a} \delta^{a} x^{a} N^{a}$ effective job searchers. Firms post $v$ vacancies in total. Market frictions result in $M<\min \left\{L^{M}, v\right\}$ matches, implying

$$
f L^{M}=M\left(L^{M}, v\right)=q v
$$

where $\Theta \equiv v / L^{M}$ denotes labor market tightness. Only a fraction $f(\Theta)$ of search units and a fraction $q(\Theta)$ of vacancies are matched. Linear homogeneity of $M(\cdot)$ implies $f^{\prime}(\Theta)>0>q^{\prime}(\Theta)$ and $f(\Theta)=\Theta q(\Theta)$. ${ }^{10}$ The matching rates $f$ and $q$ are taken as given by individual agents.

A firm with a vacancy finds a suitable worker with probability $q$ and with probability $\phi^{a} \equiv \zeta^{a} \delta^{a} x^{a} N^{a} / L^{M}$ that person is of type $a$. By definition, $\Sigma_{A} \phi^{a}=1$. The effective manpower is

$$
L_{t}^{D}=\sum_{a} l_{t}^{a} \theta_{t}^{a} \phi_{t}^{a} q_{t} v_{t}, W_{t}^{D}=\sum_{a}\left(1+t_{t}^{E, F}+t_{t}^{F, F}\right) w_{t}^{a} l_{t}^{a} \theta_{t}^{a} \phi_{t}^{a} q_{t} v_{t} .
$$

The wage bill $W^{D}$ depends on the wage $w^{a}$ per efficiency unit and is inflated by employer contributions at rates $t^{E, F}$ and $t^{F, F}$, respectively.

10 Use $M=M_{0}\left(L^{M}\right)^{\eta} v^{1-\eta}$ and get $f=M_{0} \Theta^{1-\eta}, q=M_{0} / \Theta^{\eta}$ and $f=\Theta \cdot q$. 
Firms produce output $F\left(K, L^{D}\right)$ using capital $K$, depreciating at rate $\delta^{K}$, and labor $L^{D}$. Installing $I^{K}$ units of equipment causes installation costs $J\left(I^{K}, K\right)$, measured in terms of foregone output. Acquisition prices and internal adjustment costs add up to $I^{K}+J$. After financing with retained earnings, the firm pays dividends $\chi$, net of a profit tax $T^{K}$,

$$
\begin{aligned}
\chi_{t} & =F_{t}-J_{t}-\kappa v_{t}-W_{t}^{D}-I_{t}^{K}-T_{t}^{K}, \\
T_{t}^{K} & =t_{t}^{k}\left(F_{t}-J_{t}-\kappa v_{t}-W_{t}^{D}-\delta^{K} K_{t}\right) .
\end{aligned}
$$

Maintaining a vacancy costs $\kappa$ units of output, leading to recruitment costs $\kappa v$.

Denoting end of period firm value by $V_{t}$, the Bellman equation of firm maximization is

$$
V\left(K_{t}\right)=\max _{v_{t}, I_{t}^{K}} \chi_{t}+\frac{G V\left(K_{t+1}\right)}{R_{t+1}} \text { s.t. } G K_{t+1}=I_{t}^{K}+\left(1-\delta^{K}\right) K_{t} .
$$

Denoting the shadow price of capital by $\lambda^{K} \equiv \partial V / \partial K$, optimality and envelope conditions are

$$
\frac{\lambda_{t+1}^{K}}{R_{t+1}}=1+\left(1-t^{k}\right) J_{I} \text { and } \lambda^{K}=\left(1-t^{k}\right)\left(F_{K}-J_{K}\right)+t^{k} \delta^{K}+\frac{\left(1-\delta^{K}\right) \lambda_{t+1}^{K}}{R_{t+1}} .
$$

This system determines capital accumulation as in the q-theory of investment. Normalizing adjustment costs to zero in a stationary state $\left(J=J_{I^{K}}=J_{K}=0\right)$ yields a simple condition for long-run capital demand, $F_{K}-\delta^{K}=r /\left(1-t^{k}\right)$. In a small open economy, the capital labor ratio is entirely determined by the world interest rate.

Firms post vacancies until the marginal cost $\kappa$ is equal to the marginal benefit of hiring,

$$
\kappa=q_{t} \sum_{a} \phi_{t}^{a} l_{t}^{a} \theta_{t}^{a}\left[F_{L}-\left(1+t_{t}^{E, F}+t_{t}^{F, F}\right) w_{t}^{a}\right] .
$$

With probability $q$ the firm locates a worker, and with probability $q \phi^{a}$, it gets one of type $a$, working $l^{a}$ hours with skills $\theta^{a}$. The firm's job rent per efficiency unit is $F_{L}-\left(1+t^{E, F}+t^{F, F}\right) w^{a}$. 
Once matched, the worker and firm must agree on a wage. A higher wage boosts the worker's surplus, given by the square bracket of (12), which can be written as

$$
\begin{aligned}
& \Upsilon^{a} \equiv \Gamma^{a} \frac{w^{a} l^{a}}{1+t^{c}}-\varphi_{L}^{a}-h^{p, a}+\frac{e^{a} F_{E}^{a}}{1+t^{c}} \frac{\gamma^{a} \bar{\chi}_{t+1}^{a}}{R_{t+1} \Omega_{t+1}^{a}}, \\
& \Gamma_{t}^{a} \equiv\left(1-b^{U}\right)\left(1-t_{t}^{w, a}\right)\left(1-t_{t}^{E}-t_{t}^{F}\right)+\frac{\sigma_{t}^{F}}{x_{t}} \bar{s}_{t}^{F, a}+\frac{\sigma_{t}^{M}}{x_{t}} m^{a}\left(1-b^{1}\right) \frac{\gamma^{a} \bar{\lambda}_{t+1}^{E, a}}{R_{t+1} \Omega_{t+1}^{a}} .
\end{aligned}
$$

The gains from search reflect the increase in life-time utility from accepting a job offer. A worker's surplus also reflects the size of future pensions conditional on today's earnings. The factor $\Gamma^{a}$ shows how the surplus changes when the job pays one CHF more gross income $w^{a} l^{a}$, taking account of the adjustment of taxes and benefits that are related to gross income.

To see, how the wage bargain affects the worker's job rent, we rewrite (24) in terms of the reservation wage $w_{R}^{a}$, as defined in (25) below, $\Upsilon^{a}=\left(w^{a}-w_{R}^{a}\right) \Gamma^{a} l^{a} /\left(1+t^{c}\right)$. The reservation wage is the minimum gross wage per hour that makes the worker indifferent between accepting or rejecting the match. A gross wage in excess of this leaves a strictly positive job rent, making the worker keen to accept. However, a higher wage reduces the firm's surplus, as discussed in (23). The firm's reservation wage is the maximum wage that leads to a non-negative job rent, $F_{L} /\left(1+t^{E, F}+t^{F, F}\right) \geq w^{a}$. If the wage were higher, the firm would make a loss when employing the worker. The bargaining solution maximizes the Nash product, $\max _{w^{a}}\left(w^{a}-w_{R}^{a}\right)^{\xi}\left[F_{L}-\left(1+t^{E, F}+t^{F, F}\right) w^{a}\right]^{1-\xi}$, where multiplicative terms have no influence on the solution and are dropped. The wage per hour is equal to

$$
\begin{aligned}
w_{t}^{a} & =\frac{\xi \cdot F_{L}}{1+t_{t}^{E, F}+t_{t}^{F, F}}+(1-\xi) \cdot w_{R, t}^{a}, \\
w_{R}^{a} \equiv & \frac{\left(1+t^{c}\right)\left(\varphi_{L}^{a}+h^{p, a}\right)-\frac{e^{a} F_{E}^{a} \gamma^{a} \bar{\chi}_{t+1}^{a}}{R_{t+1} \Omega_{t+1}^{a}}}{\Gamma^{a} l^{a}} .
\end{aligned}
$$

In the absence of a welfare state, the reservation wage just compensates for work effort and foregone home production during unemployment, $\varphi_{L}^{a}+h^{p, a}$. On the other hand, accepting employment has the added advantage of on the job 
training which strengthens future earnings, leading workers to accept employment at a lower wage. The gains from training, $e^{a} F_{E}^{a} \gamma^{a} \bar{\chi}_{t+1}^{a} /\left(R_{t+1} \Omega_{t+1}^{a}\right)$, reduce the reservation wage. Wage bargaining results in an average of the firm's and worker's reservation wages. A strong bargaining position of workers (high $\xi$ ) pushes up the wage.

Bargaining leads to tax shifting. Employers' contributions, $t^{E, F}$ and $t^{F, F}$, are a pure factor tax which reduces the firm's reservation wage and is partly shifted to workers. The consumption tax, on the other hand, erodes workers' purchasing power. To compensate, they demand a higher reservation wage so that consumption taxes get partly shifted to firms. Finally, higher wage taxes and social contributions reduce $\Gamma^{a}$ and boost the reservation wage, leading workers to insist on higher wages. Employment raises future pensions, both in the earnings linked and capital funded pillar, which squeezes implicit contribution taxes and reduces wage demands of workers. Note the term $1-b^{1}$. When unemployment benefits are added to the assessment base (positive $b^{1}$ ), unemployment becomes less detrimental since it still creates pension claims. This also strengthens the worker's fallback position and her wage. Finally, a higher replacement rate $b^{U}$ in unemployment insurance clearly drives up wages.

\subsection{General Equilibrium}

Aggregation of the OLG model is in two stages: (i) analytical aggregation of agents in the same age state $a$ but with different life-cycle histories, into a common age group; ${ }^{11}$ and (ii) aggregation across age groups, giving macroeconomic variables such as $A \equiv \Sigma_{A} A^{a}$. The assumed reverse insurance noted in (5) redistributes accidental bequests from the deceased to surviving persons. The break even condition implies that the individual interest factor $R \gamma^{a}$ becomes $R$ in the aggregate. After aggregation, macroeconomic asset accumulation is given by

$$
G A_{t+1}=R_{t+1}\left[A_{t}+Y_{t}+Z_{t}-\left(1+t_{t}^{c}\right) C_{t}\right]
$$

11 With constant transition rates $\omega^{a}$, stocks become heterogeneous, depending on time spent in each state. Assets of an individual with life-cycle history $\alpha$ are $A_{\alpha, t}^{a}$, where we suppressed $\alpha$ in the preceeding sections. Analytical aggregation, much in parallel to Blanchard (1985), collects assets of agents in the same state but with different histories into $A_{t}^{a} \equiv \Sigma_{\alpha} A_{\alpha, t}^{a} N_{\alpha, t}^{a}$ etc., see Keuschnigg and Keuschnigg (2010) for details. When variables are symmetric within a group, aggregation simply yields $Z_{t}^{a} \equiv z_{t}^{a} N_{t}^{a}$. Disaggregate results are available to the level of an age group, see Table 2 . 
where $Y \equiv \Sigma_{a} Y^{a}$ and $Y^{a}=x^{a} \bar{y}^{a} \theta^{a}+\left(1-x^{a}\right)\left(1-t^{w, a}\right) \sum_{j} P^{j, a}$. Note $x^{a}=1$ for prime age workers and $x^{a}=0$ for fully retired persons. The retirement decision implies $0<x^{a}<1$ for the retiring age group. With these definitions, we recover (4) and (14) while the wage related income of fully retired persons consists of pensions only.

Writing end of period assets as $\tilde{A}^{F, a}=A^{F, a}+x^{a} T^{F, a}-\left(1-x^{a}\right) P^{F, a}$, pension funds accumulate capital by $G A_{t+1}^{F}=R_{t+1}^{F} \Sigma_{a} \tilde{A}_{t}^{F, a}$. Residual assets of the deceased are again redistributed to surviving agents in terms of a return premium $1 / \gamma^{a}$ which cancels out upon aggregation. Given that administrative costs reduce the return by $\rho^{F} R$ percentage points, i.e. $R^{F}=\left(1-\rho^{F}\right) R$, and denoting administrative resource costs by $\Upsilon^{F} \equiv \rho_{a}^{F} \tilde{A}^{F, a}$, accumulation of pension fund assets in terms of the market rate of return follows

$$
G A_{t+1}^{F}=R_{t+1}\left[A_{t}^{F}+\sum_{a} x_{t}^{a} T_{t}^{F, a}-\sum_{a}\left(1-x_{t}^{a}\right) P_{t}^{F, a}-\Upsilon_{t}^{F}\right] .
$$

Aggregate pension fund assets grow with contributions (see $T^{F, a}$ as in (5)) but decline with pension outlays and administrative costs.

The model is closed by stating the remaining public sector constraints. The PAYG pillar does not accumulate assets but may possibly receive a subsidy $Z^{P}$ from the general budget if pension outlays exceed contribution revenues,

$$
Z_{t}^{P}=\sum_{a}\left[\left(1-x_{t}^{a}\right)\left(P_{t}^{E, a}+P_{t}^{L, a}\right)-x_{t}^{a} \delta_{t}^{a}\left(t_{t}^{E}+t_{t}^{E, F}\right)\left(1-u_{t}^{a}\right) w_{t}^{a} l_{t}^{a} \theta_{t}^{a}\right]
$$

The general government spends on unemployment benefits $B=\Sigma_{a} b^{a} u^{a} \delta^{a} x^{a} \theta^{a}$, social assistance $Z^{S A}=\sum_{a} s^{a}\left(1-\delta^{a}\right) x^{a} \theta^{a}$, other transfers to households $Z=\sum_{a} z^{a} N^{a}$, educational infrastructure $I^{H}=\Sigma_{a} I^{a}\left(1-u^{a}\right) \delta^{a} x^{a} N^{a}$, public consumption $C^{G}$, and on debt service. It collects wage, corporate and consumption taxes. Wage tax revenue amounts to

$$
T_{t}^{W}=\sum_{a} t_{t}^{w, a}\left[\left(1-t_{t}^{E, a}-t_{t}^{F, a}\right)\left(1-u_{t}^{a}\right) l_{t}^{a} \delta_{t}^{a} x_{t}^{a} w_{t}^{a} \theta_{t}^{a}+\left(1-x_{t}^{a}\right) \sum_{j} P_{t}^{j, a}\right]
$$

When the government runs a net deficit, it issues new debt. Public debt grows by 


$$
G D_{t+1}^{G}=R_{t+1}\left[\begin{array}{l}
D_{t}^{G}+C_{t}^{G}+I_{t}^{H}+Z_{t}^{P}+B_{t}+Z_{t}^{S A} \\
+Z_{t}-\left(T_{t}^{W}+T_{t}^{K}+t_{t}^{c} C_{t}\right)
\end{array}\right]
$$

In capital market equilibrium, household assets and pension funds are invested in domestic equity and international bonds where $D^{F}$ is the country's net foreign asset position,

$$
A_{t}+A_{t}^{F}=V_{t}+D_{t}^{F}+D_{t}^{G} \text {. }
$$

Given a surplus $T^{B}$ in the trade balance, an open economy accumulates net foreign assets

$$
\begin{aligned}
G D_{t+1}^{F}= & R_{t+1}\left(D_{t}^{F}+T_{t}^{B}\right), \\
& \text { where } T_{t}^{B}=F_{t}-\Upsilon_{t}^{F}-\kappa_{t}-J_{t}-I_{t}^{K}-I_{t}^{H}-C_{t}^{G}-C_{t} .
\end{aligned}
$$

The current account follows from Walras' Law and reflects the balance of savings and investment.

An equilibrium is found when private behavior is optimal, budget constraints are fulfilled, and markets clear. Given search frictions, labor market clearing requires that hiring by firms is equal to employment by households, or $f L^{M}=q v$ in (19). Labor market behavior of households differs across life-cycle stages, allowing us to characterize the life-cycle incidence of pension reform and other public policy. For example, the unemployment rate in age group a (representing 40 to 49 years old) is $u^{a}=1-\zeta^{a} f$. We also state the average unemployment rate by computing

$$
\bar{u}=\frac{\sum_{a} u^{a} \delta^{a} x^{a} N^{a}}{\sum_{a} \delta^{a} x^{a} N^{a}} .
$$

Applying the same procedure to the other dimensions of labor supply, we arrive at the decomposition of aggregate employment in (1). 


\section{Model Calibration}

To prepare for quantitative policy analysis, we first review the empirical evidence on labor market behavior, investment and savings, and then discuss other institutional and economic parameters. The last subsection reviews the aging projections in Switzerland.

\subsection{Behavioral Elasticities}

Hours Worked: The classical channel for labor supply is on the intensive margin. People respond by adjusting hours worked, or intensity of work effort on the job. They work more if the current real wage net of taxes is high and if current earnings create additional benefits such as higher unemployment benefits, or higher future pensions in an earnings linked system, see (10). The econometric estimates of Disney (2004) show that men are not very responsive to a change in the effective contribution tax while women's activity rates are strongly affected. These findings are consistent with much of the empirical labor supply literature. Blundell and MaCurdy (1999) and Meghir and Phillips (2008) survey the large literature. The calibrated model supports a reasonable consensus value for the wage elasticity of hours worked equal to .3 .

Job Search: A large empirical literature studies the influence of unemployment insurance on reservation wages and search intensity, see the reviews by ATKINson and Micklewright (1991) and Krueger and Meyer (2002). According to a study by BELOT and van Ours (2001) for 18 OECD countries, a one percent increase in the replacement ratio results in a .7 percent rise in the unemployment rate. They also estimate that a one percentage point increase in the income tax rate shrinks the unemployment rate by .12 percentage points. GERFIN and Lechner (2002) and Gerfin et al. (2005) find positive effects for a wage subsidy for temporary jobs on employment in the regular Swiss labor market. The estimates of SCARPETTA (1996) imply that a 10\% increase in the replacement ratio of unemployment benefits leads to an unemployment rate higher by about 1.3 percentage points. This coefficient compares with an estimate of 1.7 in LAYARD et al. (1991), 1.1 in NiCKEL (1997) and roughly the same in BlanCHARD and Wolfers (2000). The model exhibits a search elasticity with respect to the replacement rate of 1.2 .

Labor Market Participation: Immervoll et al. (2007) summarize the recent literature on labor market participation. Eissa and Hoynes (2004) point out that 
participation elasticities differ substantially across different groups. Low skilled households react strongly to participation incentives, and women have a much higher elasticity than men. In contrast, skilled people with high earnings respond only weakly to participation incentives (see BLUNDELL, 1995). Model calibration yields a semi-elasticity of .2, meaning that a 10 percent increase in replacement income triggers a reduction of the participation rate by 2 percentage points.

Retirement Decision: The Gruber and Wise (1999, 2004, 2007) worldwide project and subsequent updates provide a documentation of participation tax rates and their impact on retirement behavior. BütLER et al. (2004) and BüETLER (2009) discuss the impact of retirement benefits on retirement in Switzerland. Dorn and Sousa-Poza (2010) analyze the determinants of retirement in an international context. They find that more generous early retirement provisions of the social security system create both more voluntary and more involuntary early retirement. The incidence of early retirement not only increases because more workers freely choose to retire, but likely also because the social security system creates incentives for firms to shed older workers. For Germany, BöERsCH-SUPAN (2000) estimates that a decrease in benefits by $12 \%$ would reduce the retirement probability of the 60 years old from 39.3 to $28.1 \%$, implying a semi-elasticity of retirement equal to .93 . However, this value falls with age and is estimated at .45 for 64 year-olds. At the average retirement age of 64 , the model supports a retirement elasticity of .5 .

Life-Time Training: Old-age insurance can affect incentives for education and life-time training. Training investments become more attractive if they yield a larger present value of income gains and pay off over a longer working period. For this reason, postponing retirement age tends to encourage training. LAU and PoutvaAra (2006), for example, analyze the impact of aging and the pension system on training. In particular, they emphasize that an increase in retirement age and a strong link between pensions and contributions encourage investment in education. ${ }^{12}$ Fouarge and Schils (2009) empirically investigate to what extent older workers' investments in training depend on the pension system. In a field experiment, Messer and Wolter (2009) show that the voucher had a significant causal impact on participation in training programs. GörLITz (2009) finds that a voucher program which was implemented in the German federal state of North Rhine-Westphalia and which increased training incentives for employees

12 This also relates to the theoretical findings in Kalemli-Ozcan (2002) and Soares (2005). See also JAAG (2009) for an analysis of aging and education decisions. 
by reducing training costs by $50 \%$ resulted in an increase in the share of establishments that invest in training by approximately 5 percentage points. KANE (2006) provides a summary of studies discussing the impact of tuition on enrollment choices. Using different data sets and different identification methods, various studies seem to arrive at the same conclusion: An increase in tuition of $\$ 1,000$ results in a decrease in college enrollment of 4 to 6 percentage points.

Savings and Investment: Savings and investment result from intertemporal choice with perfect foresight. Households save to ensure smooth consumption in the face of uneven life-cycle income patterns. A larger pension replacement rate reduces private savings since agents do not need to save themselves when the pension system provides income. In contrast, a longer remaining lifetime and early retirement boost savings since individuals must accumulate more capital to be able to maintain their living standard over a prolonged retirement period. Higher net interest rates encourage savings. Smoothing consumption depends on the intertemporal elasticity of substitution with estimates fluctuating around .5. We take a conservative estimate of .35 in Table 1. Capital accumulation results from intertemporal investment decisions of domestically owned firms. In the long-run, the elasticity of investment with respect to the user cost of capital varies around unity which is consistent with a substitution elasticity between capital and labor equal to around .8. Adjustment costs imply that capital accumulation is a smooth process even in an open economy with a fixed interest rate. Altig and Carlstrom (1999) and Altig et al. (2001), among others, discuss these parameters.

\subsection{Economic and Institutional Parameters}

Table 1 shows key data and parameters of the simulation model. The numbers depict the growth trend of the Swiss economy with 2005 as a reference year. The average unemployment rate is $3.6 \%$ in the initial steady state (ISS). It varies during the life-cycle, being larger for younger workers (see Table 2). The labor market participation rate is $74 \%$ on average. The retirement age in Switzerland, equal to about 64 on average, is relatively high in comparison with other countries. Approximately $40 \%$ of workers 60-69 years-old are still active in the labor market. Table 2 shows the age structure of the population: the 60-69 years-old represent roughly $13 \%$ of the total population. The old age dependency ratio (defined as the ratio of workers to retirees) is $28 \%$ in the initial steady state (ISS).

Except for the retirement decision, Table 1 shows the effective tax rates for the first age group, which corresponds to the 20-29 years old. The effective tax rate on intensive labor supply (hours worked by the employed) is defined in (9-10) 
Table 1: Model Parameters

\begin{tabular}{|c|c|c|}
\hline \multicolumn{3}{|c|}{ Households and Production } \\
\hline$r$ & 0.035 & annual real interest rate \\
\hline$g$ & 0.018 & growth rate of labor productivity \\
\hline$\delta$ & 0.100 & depreciation rate of capital \\
\hline$\sigma^{K}$ & 0.800 & elasticity of capital labor substitution \\
\hline$\sigma^{C}$ & 0.350 & intertemporal elasticity of substitution \\
\hline $\bar{u}$ & 0.036 & average unemployment rate \\
\hline $\bar{\delta}$ & 0.740 & average participation rate \\
\hline$x^{*}$ & 0.400 & retirement age/participation rate $60-69$ years old \\
\hline$N^{R} / N^{W}$ & 0.277 & retiree-worker ratio \\
\hline \multicolumn{3}{|c|}{ Welfare System } \\
\hline$\rho^{u}$ & 0.540 & replacement rate of unemployment benefits \\
\hline$\rho^{a}$ & 0.230 & replacement rate of social assistance \\
\hline$\tau_{1}^{L}$ & 0.223 & effective tax rate, hours worked \\
\hline$\tau_{1}^{P}$ & 0.280 & effective tax rate, prime age participation \\
\hline$\tau_{1}^{S}$ & 0.651 & effective tax rate, job search \\
\hline$\tau^{R}$ & 0.510 & effective tax rate, continued work \\
\hline
\end{tabular}

Note: ${ }^{*}$ The retirement date corresponds to the share of active house-holds in the group 60-69 years old.

and mirrors the wage tax burden that is $26 \%$ on average. In addition, the effective tax rate is inflated by the tax component of PAYG pension contributions and the consumption tax. The effective rate is about $22 \%$ for the youngest workers. According to Table 1, the effective participation tax rate, defined in (13), at $28 \%$ is rather low and not much higher than the effective wage tax burden, while the effective tax on job search, stated in (12), is almost twice as big. ${ }^{13}$ There are two

13 The rate of $65 \%$ is well in the range of values compiled by Immervoll et al. (2007) for Europe. Note that these authors do not distinguish between participation and subsequent job search. 
reasons for this pattern. First, unemployment benefits are much more generous than social assistance. When moving from unemployment into a job, workers face much higher opportunity costs, compared to giving up social assistance and other benefits when moving out of non-participation. Second, only a quarter of the non-participating are covered by social assistance so that, on average across all households, social benefits are less important for the participation decision. Finally, the participation tax rate on the retirement decision, as stated in (18), is equal to $51 \%$, which is relatively low by international standards. The Swiss PAYG pillar includes pension supplements for each year of postponed (discounts per year of premature) retirement equal to $6.8 \%$. The funded pillar involves only a low effective tax rate by construction.

Table 2 reports life-cycle and demographic parameters. We can contrast the unemployment experience of younger workers early in their career with the labor market status of older workers near retirement. The life-cycle income profile depicts the usual hump-shaped pattern. Income of retired groups mostly consists of pensions. Disposable income of active groups reflects life-cycle wage profiles and a directly progressive wage tax which is highest for people with earnings at the peak of their career. As is typical for life-cycle models, the marginal propensity to consume out of life-time wealth increases with age so that the oldest persons have the highest consumption propensity and the lowest savings rate because they expect the shortest remaining life-time.

The model captures the institutional characteristics of the Swiss pension system with three pillars: the PAYG system, the mandatory private pension system, and voluntary private savings with preferential tax treatment as a third pillar. PAYG spending represents $6.6 \%$ of GDP, of which about $3 / 4$ are covered by contributions. The gross replacement rate in the PAYG pillar is $40 \%$. Only $60 \%$ of PAYG pensions are earnings-linked. The flat component reflects the fact that the taxbenefit-link is eliminated for minimum pensions of low income households and maximum pensions of people with earnings higher than the upper contribution ceiling. The division into a flat and a variable part is important for the size of the tax component of contributions: the larger the share of the flat part in the PAYG pension is, the higher is the contribution tax. The total effective average employee and employer contribution is about $8.3 \%$, yielding an implicit tax rate of about $2 \%$ in the youngest age group.

Adding funded and mandatory PAYG pensions yields a gross replacement rate of about $60 \%$ of the last wage income in total. Of total pension income, $65 \%$ stems from the PAYG and 35\% from the funded pillar. Funded pensions not only reflect accumulated contributions but also earned interest. The tax component of funded pillar contributions is clearly lower but remains positive 
Table 2: Demographic and Life-Cycle Parameters

\begin{tabular}{lccccccccc}
\hline Age Group & $a$ & 1 & 2 & 3 & 4 & 5 & 6 & 7 & 8 \\
\hline Cohort & & $20-29$ & $30-39$ & $40-49$ & $50-59$ & $60-69$ & $70-79$ & $80-89$ & $90-99$ \\
Population share & $N^{a} / N$ & 0.20 & 0.19 & 0.18 & 0.16 & 0.13 & 0.09 & 0.04 & 0.01 \\
Age retention rate & $\omega^{a}$ & 0.90 & 0.91 & 0.91 & 0.92 & 0.93 & 0.95 & 0.97 & 1.00 \\
Survival rate & $\gamma^{a}$ & 1.00 & 0.99 & 0.99 & 0.98 & 0.97 & 0.95 & 0.93 & 0.90 \\
\hline Marg. prop. consume & $1 / \Delta^{a}$ & 0.03 & 0.04 & 0.05 & 0.05 & 0.06 & 0.08 & 0.10 & 0.12 \\
Disp. wage income & $\bar{y}^{a}$ & 0.67 & 0.96 & 1.11 & 1.10 & 0.75 & 0.67 & 0.63 & 0.60 \\
Wage tax rate & $t^{u, a}$ & 0.24 & 0.26 & 0.28 & 0.29 & 0.25 & 0.25 & 0.25 & 0.25 \\
Labor productivity & $\bar{\theta}^{a}$ & 1.43 & 1.95 & 2.23 & 2.26 & 1.85 & - & - & - \\
Participation rate & $\delta^{a}$ & 0.65 & 0.75 & 0.80 & 0.80 & 0.65 & - & - & - \\
Unemployment rate & $u^{a}$ & 0.04 & 0.04 & 0.03 & 0.03 & 0.03 & - & - & - \\
\hline
\end{tabular}

Note: $1-\omega^{a}$ is the transition rate to the next age state. $1-\gamma^{a}$ is the mortality rate in each age state.

due to administrative costs. We assume that overhead costs consume $1 \%$ of the return on pension assets. Hence, pension funds generate an effective return of $2.5 \%$ which is lower than the market interest rate of $3.5 \%$. Total pension assets amount to $125 \%$ of GDP.

\subsection{Demographic Change In Switzerland}

The demographic scenario published by the Swiss Federal Statistical Office projects population growth from $7.2 \mathrm{~m}$ in 2005 to $8.1 \mathrm{~m}$ in 2050 . This increase is not due to immigration or higher fertility but rather to longer life-times. Lower mortality rates and higher life-expectancy result in a larger proportion of old people. The dependency ratio, measuring the ratio of people older than 65 and the population of 20 to 64 years old, must inevitably rise. The share of over 65 years old is expected to reach $28 \%$ of the total population, compared to $16 \%$ in 2005 . Hence, the dependency ratio will almost double until 2050 (see Figure 1).

Demographic change is governed by three important factors: mortality and life-expectancy, fertility, and migration. There are three official scenarios with respect to life-expectancy in Switzerland (see Bundesamt für Statistik, 2006). 
Figure 1: Old Age Dependency Ratio

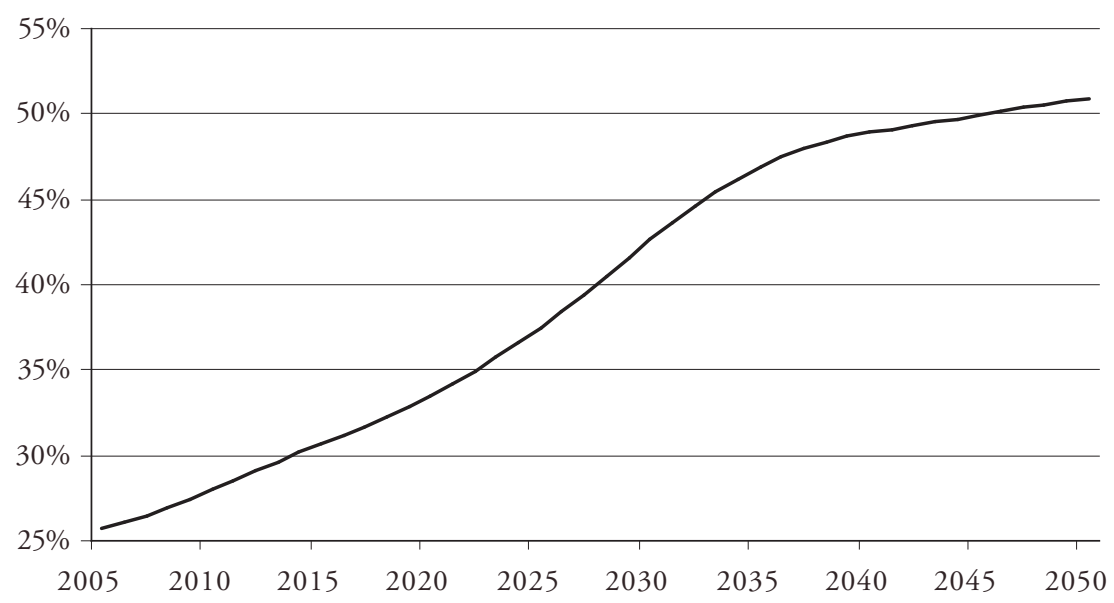

An intermediate scenario assumes that better prevention and continuous medical advancements raise life-expectancy at birth to 85.0 years for men and 89.5 years for women in 2050, compared to 78.6 and 83.7 years, respectively, in 2005. The average fertility was 1.4 children per woman in 2005 . The intermediate scenario assumes that increased public awareness of the families' economic and social importance leads to increased support. As a result, the currently low fertility is expected to rise somewhat. Finally, the average scenario assumes that current trends in net migration will be extended into the future. The free movement of persons will yield only transitory effects on the net immigration from new EU member states. According to the scenario, net immigration which was roughly 40,000 persons in 2005, will decrease from 2012 to 2020 to 10,000 persons and then remain unchanged.

A restriction in using a model of balanced growth is that simulations must assume the economy to start from an initial stationary state. Neither the economy nor the population structure are in a steady state at any point in time so that data must be averaged over time and adjusted to some degree to reconcile them with the requirements of a balanced growth equilibrium. However, the key macroeconomic and demographic indicators, such as the current dependency ratio, are correctly implemented. According to demographic forecasts, the oldage dependency ratio will double in the long-run and eventually reach a ratio of roughly 0.5 . As Figure 2 shows, the survival rates increase already in earlier 
Figure 2: Survival Probabilities

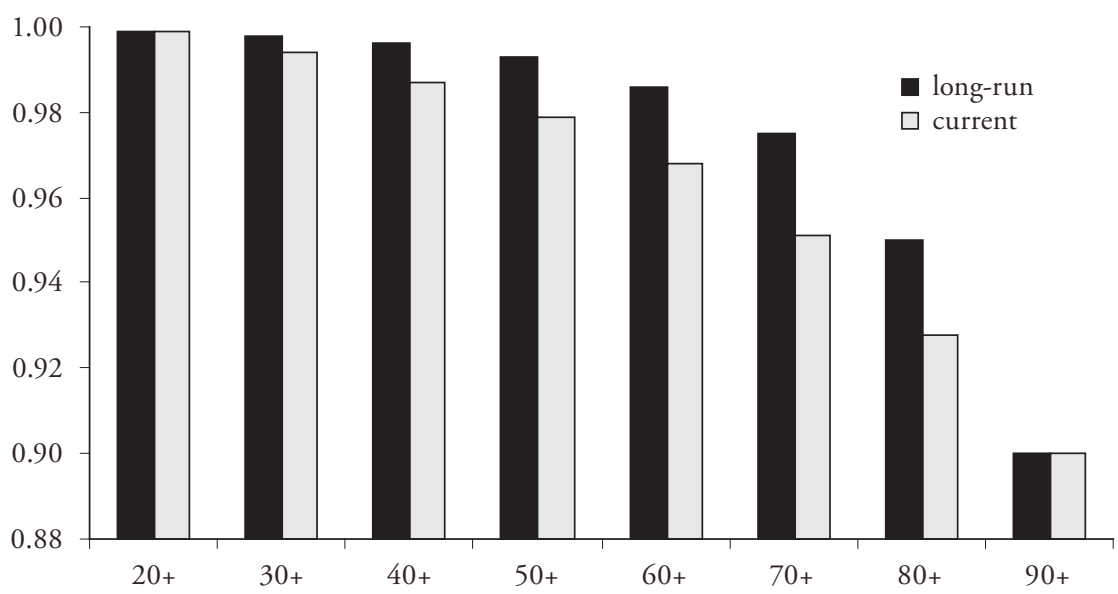

stages of the life-cycle. A 60 year old person will reach more probably the age of 70 , and a 70 year old is more likely to live until the age of 80 , etc. Lower mortality rates at younger ages imply that a much larger share of people reaches the age of 90-99 years old.

For a given inflow of new borns, lower mortality rates change both the structure and the size of the population. Keeping the inflow of newborns constant, the size of the older population grows when mortality declines. Figure 3 shows how, in turn, the share of older age groups rises while the share of younger cohorts shrinks. The bars illustrate the relative weights. The long-run age composition is determined exclusively by survival and mortality rates. A lower permanent inflow of new generations, brought about by a lower fertility rate or as a result of immigration, cannot change the demographic structure in the long-run but can only scale down total population. The inflow in the model is set such that population size grows by $10 \%$ in the long-run, roughly in line with the above mentioned demographic projections for Switzerland. 
Figure 3: Population Structure

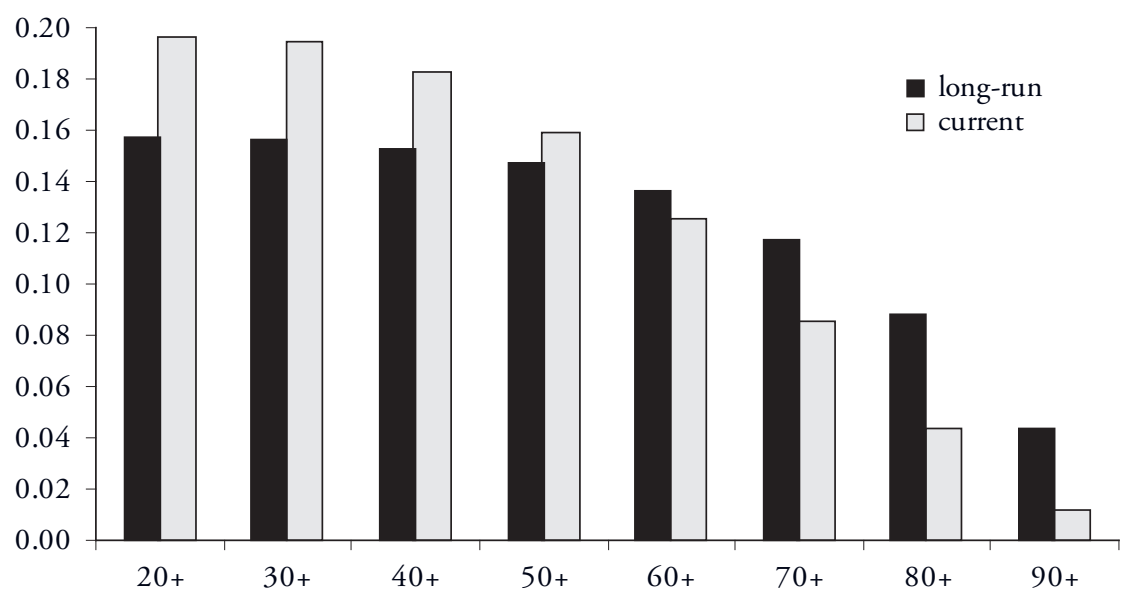

\section{Quantitative Policy Analysis}

\subsection{Long-Run Effects of Aging}

We first quantify the long-run economic effects of aging as discussed above. The scenario consists of three elements: (i) the dependency ratio roughly doubles due to increased longevity; (ii) the total population rises by $10 \%$ in the long-run; and (iii) the working age population declines by about $6 \%$. To provide a benchmark, the government is assumed to follow a passive strategy, leaving current benefit rules unchanged and merely adjusting wage taxes and contribution rates to balance budgets. The long-run effects are reported in column 'Age' of Table 3. Contribution rates and wage tax rates must strongly increase, and the pure demographic effect implies a large decline in per capita income (see Keuschnigg et al., 2010, for an analytical argument to this effect). The higher tax and contribution rates strongly discourage labor supply, leading to a further reduction in per capita income beyond the demographic and mechanical budget effects.

Table 3 shows a large long-run impact of aging on public finances and the economy. Fiscal balance requires to add 7.1 percentage points to the wage tax schedule over the entire income range. For example, the wage tax rate of the 20-29 years old would increase from 22 to 32\%, and similarly for all other groups. On top of that, contribution rates to the PAYG pillar of both employees 
and employers must also be raised by the same amount. Altogether, the statutory labor tax burden rises by 21 percentage points. While employer contributions are a full factor tax, employee contributions only partly count as a tax. The effective tax on hours worked rises by roughly 10 percentage points, and similarly the participation tax. Aggregate labor supply thus shrinks due to fewer hours worked and lower participation of prime age workers. The effective tax rate on job search rises to a lesser extent since unemployment benefits are partly indexed to net wages so that a higher wage tax burden not only reduces the value of work but also the value of unemployment. Nevertheless, the tax distortion still rises substantially, from an already high level, and leading to an increase in the unemployment rate from $3.6 \%$ in the absence of aging to $5.5 \%$. This large effect is also due to higher firm contributions which inflate wage costs and discourage job creation.

The scenario induces a moderate tendency for early retirement which reflects offsetting forces. On the one hand, increased longevity leads to a large reduction in capital funded pensions which, other things equal, encourages postponed retirement. On the other hand, the tax changes favor early retirement. Although higher wage taxes reduce both active earnings and pensions, higher contribution rates exclusively diminish income from continued participation and, thus, makes work relatively less attractive compared to retirement. This second effect dominates and induces early retirement which eventually reduces the participation rate among the 60-69 years old from .4 to .35 . The scenario implies diverse training incentives for different life-cycle groups which overall result in moderately higher average labor productivity. With this exception, all labor market responses work to magnify substantially the demographically induced reduction of the workforce. Total employment thus falls by $11.8 \%$ in absolute levels. Since aging has no consequences for long-run capital intensity in a small economy with a fixed interest rate, the GDP level shrinks by the same percentage. However, GDP is divided over a $10 \%$ larger population so that per capita GDP falls by $20 \%$. Starting from this benchmark, we next turn to the potential of several policy strategies to cushion the economic impact of aging.

\subsection{A Comprehensive Policy Approach}

The effects of aging on the financing of social security can be offset in three ways: reduced benefits, higher contributions, and an increase in the retirement age. The simple analytics in Keuschnigg et al. (2010) show that increased longevity can be offset by a 'neutral' increase in the retirement age that keeps old age insurance balanced without adjustments of contribution and pension replacement rates. Intuitively, if agents currently spend three quarters of their adult life 
in work and one quarter in retirement, then each additional year of life-extension should be divided in the same way. The argument implies that an increase in retirement age is a central policy response to prevent large increases in tax rates or a decline in replacement rates.

We quantitatively evaluate a comprehensive reform package which consists of six elements: (i) raising the retirement age to boost continued participation of older workers; (ii) strengthening the tax benefit link in the PAYG pillar by eliminating the upper income ceiling for pension assessment so that benefits become earnings linked also for incomes in excess of this ceiling; (iii) eliminating unemployment benefits from the contribution base so that periods of unemployment no longer add to pension entitlements; (iv) taking measures to reduce administrative costs in the funded pillar by half a percentage point; (v) tighter monitoring of job search to cut the unemployment rate; (vi) measures to encourage life-long training to strengthen the contribution base but also to improve the employability of older workers to facilitate the increase in the retirement age. In all cases, the VAT is raised by 4 percentage points. Wage tax and PAYG contribution rates by workers and firms are endogenously adjusted to assure fiscal balance at all dates. The VAT is considerably less harmful to incentives for extensive labor supply than wage taxes because it taxes the income in both active and inactive states while the wage tax reduces only employed income. The higher VAT limits the rise in wage taxes and contribution rates so that the financing of social security becomes less damaging for labor market performance. The last six columns in Table 3 present the cumulative impact so that the last column shows the total effects of aging and policy reform relative to the status quo.

\subsubsection{Raising Retirement Age}

Raising the retirement age to keep older workers in the labor force is the central piece of the reform package. Raising the statutory retirement age by 3 years means that the regular pension will be received only at the age of 68 instead 65 , with no additional pension compensation and an unchanged replacement rate. Column 'Late' in Table 3 reports long-run effects. Comparing to column 'Age' shows the differential impact of the reform while comparing to 'ISS' gives the total impact of aging and the higher retirement age. Recall that the (exogenous) long-run expected retiree-worker ratio as a result of aging is close to 0.5 , almost twice as much as today's ratio of 0.27 . Raising the retirement age reduces the number of pensioners and augments the active workforce, leading to a much smaller increase in the dependency ratio to 0.38 . Still, the number of retirees is $40 \%$ higher than in the status quo. Hence, not only the VAT rate is up by $4 \%$, but also the wage 
Table 3: Aging and Comprehensive Social Security Reform

\begin{tabular}{lcccccccc}
\hline & ISS & Age & Late & Ceil & Un & Adm & Mon & Train \\
\hline Absolute Changes & & & & & & & & \\
Tax Increase* & 0.000 & 0.071 & 0.019 & 0.015 & 0.012 & 0.005 & 0.004 & 0.001 \\
\hline Implicit PAYG Tax** & 0.016 & 0.075 & 0.025 & 0.007 & 0.005 & 0.001 & 0.001 & -0.002 \\
Eff. Tax on Hours** & 0.223 & 0.320 & 0.243 & 0.224 & 0.223 & 0.213 & 0.216 & 0.211 \\
\hline Eff. Particip.Tax** & 0.280 & 0.382 & 0.303 & 0.283 & 0.282 & 0.272 & 0.274 & 0.270 \\
Eff. Tax on Search** & 0.651 & 0.700 & 0.663 & 0.653 & 0.625 & 0.621 & 0.620 & 0.618 \\
Eff. Retirement Tax & 0.510 & 0.556 & 0.514 & 0.400 & 0.394 & 0.365 & 0.367 & 0.361 \\
Pension Repl.Ratio & 0.600 & 0.557 & 0.582 & 0.567 & 0.559 & 0.561 & 0.562 & 0.558 \\
Retirement Date & 0.400 & 0.348 & 0.801 & 0.811 & 0.811 & 0.814 & 0.814 & 0.815 \\
\hline Participation Rate & 0.740 & 0.722 & 0.726 & 0.729 & 0.729 & 0.731 & 0.731 & 0.732 \\
\hline Unemployment Rate & 0.036 & 0.055 & 0.042 & 0.039 & 0.032 & 0.030 & 0.025 & 0.024 \\
\hline Percentage Changes & & & & & & & & \\
\hline Labor Force & & -6.952 & 1.744 & 1.933 & 1.945 & 1.999 & 1.990 & 2.027 \\
\hline Gross Wage & & -5.076 & -1.535 & -1.314 & -1.619 & -1.074 & -1.739 & -1.534 \\
\hline Hours Worked & & -1.584 & -1.223 & -0.957 & -0.962 & -0.792 & -0.850 & -0.811 \\
\hline Labor Productivity & & 0.735 & 1.291 & 1.301 & 1.324 & 1.325 & 1.317 & 2.637 \\
\hline Labor Demand & & -11.762 & -0.746 & 0.455 & 1.254 & 1.954 & 2.318 & 3.962 \\
\hline GDP p.cap. & & -19.939 & -9.944 & -8.854 & -8.129 & -7.494 & -7.164 & -5.672 \\
\hline Consumption p.cap. & & -20.193 & -10.566 & -9.413 & -9.044 & -7.213 & -7.502 & -6.001 \\
\hline Wealth p.cap. & & 11.231 & 1.025 & 2.036 & 2.381 & 1.475 & 0.957 & -0.198 \\
\hline & & & & & & & &
\end{tabular}

Note: Columns report cumulative effects. * Financing through higher wage tax and PAYG contributions. In the reform scenarios, 4 percentage points of VAT are also added. ${ }^{* *}$ Tax rate for $20-29$ years-old; (Age): Aging without reform (no use of VAT financing); (Late): increase in retirement age; (Ceil): eliminate contribution ceiling in PAYG pillar; (Un): no accumulation of pension entitlemensts of unemployed; (Adm): reduction of administrative costs in funded pillar; (Mon): monitoring of the unemployed; (Train): investment in training.

tax and contribution rates to the PAYG pillar have to rise each by 1.9 points to finance the large increase in pension spending due to longer life-spans.

The direct effect of raising retirement age is to turn the decline in the physical labor force by $6.9 \%$ into a gain of $1.7 \%$ relative to the ISS (initial steady state). Effective tax rates are still higher for all margins of labor supply, although much 
less than in the pure aging scenario. Effective tax rates shrink considerably which boosts incentives for job search and reduces the unemployment rate from 5.5 to $4.2 \%$. Importantly, training investments become more profitable since the returns to training accrue over a longer working life. Average labor productivity significantly improves by $1.3 \%$, up from $0.7 \%$ in the aging scenario. To sum up, raising the retirement age provides a strong fiscal relieve, allows for a lower tax burden and strengthens incentives on all margins of labor supply. The measure thus offsets a large part of the negative economic incentives created by aging. Consequently, the decline in total labor demand is reduced to $-0.7 \%$, a huge improvement relative to the loss of $-12 \%$ in the aging scenario. While the level of GDP is down by a moderate $-0.7 \%$, GDP per capita still declines by around $-10 \%$ on account of a larger population due to longevity. The loss in per capita GDP as a result of aging is halved. Finally, a higher retirement age strongly reduces lifecycle savings and wealth per capita since individuals need to save for a shorter remaining retirement period.

\subsubsection{Strengthening the Tax-Benefit-Link}

In Switzerland, the PAYG pillar limits benefits to a maximum amount so that contributions above an upper income threshold (equal to 79,560 Fr. per year) do no longer augment individual pensions. The existence of this income ceiling implies that pensions on incomes in excess of this threshold are no longer linked to individual earnings. In this upper income range, contributions are perceived as a full tax which adds to the general income tax and discourages labor market behavior. Currently, out of all pension payments from the PAYG pillar, 2\% refer to minimum pensions, $60 \%$ to regular earnings linked pensions, and $38 \%$ on maximum pensions above the income ceiling. In the simulation model, $40 \%$ of pensions in the status quo are flat and $60 \%$ are earnings linked. The scenario specifically assumes that the share of earnings linked PAYG pensions is raised to $90 \%$ (by adjusting up the parameter $m^{a}$ in 5) and the flat pension reduced to $10 \%$, rather than to $2 \%$. This conservative assumption should allow for somewhat higher minimum pensions to cushion other negative distributional effects such as the reduction of the real pension value due to a higher VAT rate. Finally, to avoid an increase in pension levels when a larger part of income enters the benefit assessment, the scenario also assumes a moderate reduction of the replacement rate.

Column 'Ceil' reports the total long-run impact where the differential effect of eliminating the income ceiling is seen by comparing to column 'Late'. The economic implication is to reduce the tax component in PAYG contributions 
and to reap efficiency gains by strengthening the tax-benefit-link. The required increase in wage tax and contribution rates is reduced from 1.9 to $1.5 \%$. Effective tax rates fall on all margins, and rather strongly in case of the effective retirement tax on account of a somewhat lower replacement rate. Consistent with the empirical evidence discussed in Section 3.1, retirement becomes much less sensitive to incentives when the retirement age is already very high. Hence, the old age participation rate rises only moderately. The reform stimulates labor supply on other margins as well but these effects (relative to column 'Late') remain relatively limited. As a result, total employment expands by more than one percentage point, turning a loss of $-0.7 \%$ into a gain of $0.4 \%$. GDP per capita now shrinks by $8.8 \%$, instead of $9.9 \%$. Hence, strengthening the tax-benefit-link by eliminating the income ceiling yields an income gain of roughly one percentage point of GDP.

\subsubsection{Eliminating Unemployment Benefits from Contribution Base}

The PAYG pillar in Switzerland adds unemployment benefits like any other earned income to the pension assessment base (parameter $b^{1}$ in 5). The problem with this rule is that it alleviates the consequences of unemployment and weakens job search incentives (see 12). Presumably, this rule is intended to prevent old-age poverty. This goal, however, is already addressed by the existence of minimum pensions which are raised as part of the preceding policy initiative. By eliminating this rule, pensions become linked exclusively to employment. Denying new pension entitlements during unemployment strengthens search incentives and favorably affects the unemployment rate and thereby total employment. As column 'Un' in Table 3 shows, the effective tax rate on search is reduced by 3 percentage points, leading to a significant reduction in the unemployment rate from 3.9 to $3.2 \%$. Lower unemployment saves spending on unemployment benefits and allows a small reduction in residual wage tax and contribution rates, down from 1.5 to $1.2 \%$. The gross wage falls more strongly since the reform cuts the workers' fallback option in wage bargaining. With higher job rents, firms expand labor demand by placing more vacancies, making possible the substantial reduction in the unemployment rate. The slight cut in the wage tax rate has positive side effects on other margins of labor supply. Therefore, effective employment and the level of GDP now expand by $1.3 \%$, where the differential effect amounts to almost 1 percentage point. Accordingly, the loss in GDP per capita is reduced from 8.8 to $8.1 \%$. 


\subsubsection{Reducing Administrative Costs of Funded Pillar}

The fragmentation and complexity of the funded pillar in Switzerland with a multitude of independent pension funds and relatively low returns have been criticized in the past, among others by the World Bank (Queisser and VitTas, 2000). Better supervision, more competition and more freedom of choice might yield a higher return. We cannot quantify the precise magnitude of the efficiency gain and instead assume, somewhat arbitrarily, that administrative costs can be reduced from $1 \%$ to $.5 \%$ of pension fund assets. Column 'Adm' reports the longrun effects. Due to lower administration costs, the return in the second pillar rises from 2.5 to $3 \%$ while the net interest in the capital market remains at $3.5 \%$. The contribution rate to the funded pillar is kept constant but contribution capital earns a larger interest and, ceteris paribus, results in a larger funded pension. To keep the total pension replacement rate fixed, the PAYG pension is scaled down by the same factor as the private pension is scaled up. The budgetary saving is used to cut wage tax rates as well as employee and employer contributions to the PAYG system. In general equilibrium, these rates can be cut in total by roughly 2 percentage points $(3 \times(1.2-.5)$ in the first line of Table 3$)$. Effective tax rates are thus reduced to a moderate extent which stimulates all margins of labor supply. The unemployment rate drops further to $3 \%$. Altogether, effective employment and per capita GDP expand by another .7\%, as compared to the prior scenario.

\subsubsection{Tighter Monitoring of Unemployed}

Sanctions against shirking in job search and monitoring of unemployed job seekers are often used instruments of active labor market policy. We assume that unemployment also yields some leisure utility, and that monitoring and sanctions in case of observed inactivity in job search can reduce the value of being unemployed (variable $v^{p, a}$ in 12) by a monetary equivalent of $5 \%$ of unemployment benefits. We also ignore additional administrative costs due to monitoring and assume that these activities are covered out of the existing budget for labor market policy. Column 'Mon' shows the quantitative, long-run impact. The policy measure not only boosts search incentives as in (12). In eroding the fallback option, the intervention also squeezes the reservation wage in (25) and thereby augments the total job rent which amounts to the difference between the marginal product of labor and the reservation wage. Wage bargaining splits the larger surplus between workers and firms so that the gross wage rate falls (by $1.7 \%$ instead of $1.1 \%$ ) which, in turn, boosts the job rent of firms. As a result, workers search more intensively, and firms find it more profitable to create jobs. The unemployment rate, in turn, shrinks from 3 to $2.5 \%$. The repercussions on 
the wage tax burden and on other dimensions of labor supply are basically insignificant. Overall, the effect on employment and GDP is an additional 0.4 percentage points, leading to a level effect of $2.3 \%$ relative to ISS. The loss in GDP per capita is further reduced to $7.2 \%$.

\subsubsection{Incentives for Life-Long Training}

In an aging society, training may be an important means to compensate, at least partly, for the decline in labor supply resulting from a reduced inflow of young workers. Skill accumulation rests on households' willingness to reallocate time from work to training and on public spending to provide the necessary infrastructure (see the public input $I^{a}$ in 5 , raising the private returns to training $F_{E}^{a}$ in 11 , at the cost of tax financed spending $I^{H}$ in the government budget 30 ). The scenario assumes that government raises the public input per trainee (teachers, learnings material, class-room and other resources) by one percent. Since the number of trainees rises by the positive impact on employment rates and participation, the government must raise aggregate on training $I^{H}$ by about $2.7 \%$. However, this spending item amounts only to about $5 \%$ of tax revenue in the model so that the effect on the public budget is rather limited.

Households endogenously respond by reallocating more time to training, incurring a private opportunity cost in terms of foregone wage earnings. As a result of more active private training and more generous public support, average labor productivity rises by an additional $1.3 \%$ and ends up $2.6 \%$ higher than in the ISS. The higher quality of the workforce boosts effective employment by an extra $1.6 \%$. All in all, the levels of effective employment and GDP are $4 \%$ higher than in the status quo. The loss in per capita income is limited to $5.7 \%$, down from $7.2 \%$. The repercussions on other components of aggregate labor supply are not important. One may conclude from the results of Table 3 that training is an important policy area to cushion the economic impact of aging.

\subsection{Life-Cycle Incidence}

Aging and structural social security reform may have an uneven impact on the life-cycle. Figure 4 reveals that strengthening training incentives may disproportionately benefit older workers in the long-run. The effects of training accumulate if workers respond to improved incentives over the entire working life. Postponed retirement also stimulates training since returns accrue over a longer working life. The strongest effect is probably with persons near retirement, see the discussion of (11). The skills of older workers are also of special interest since 
Figure 4: Life-Cycle Unemployment

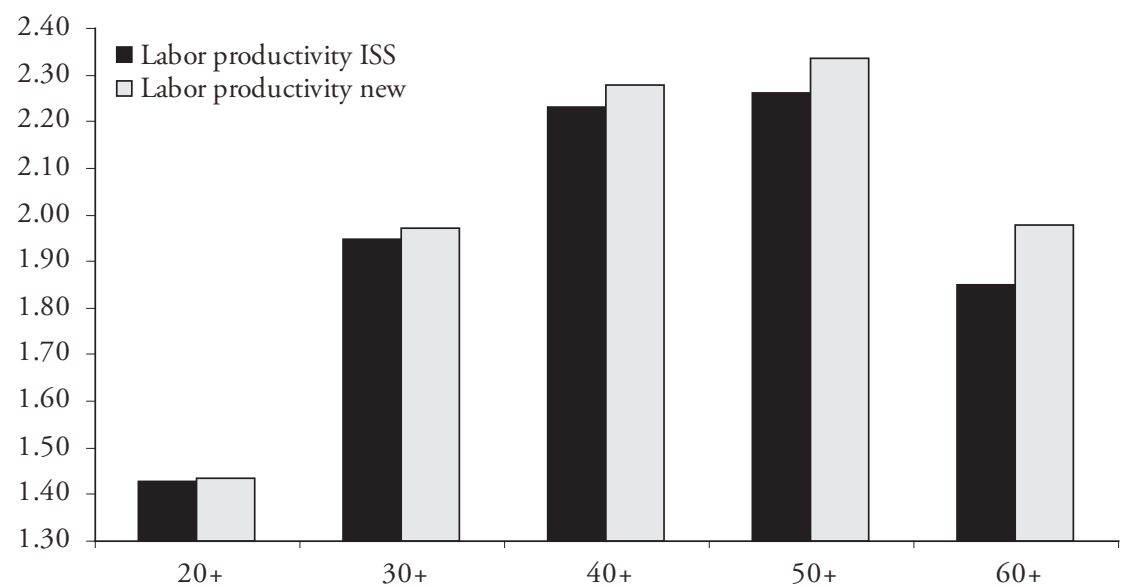

they affect their employability. Many observers are concerned that an increase in the retirement age could be ineffective because older workers may be difficult to employ. However, the simulations show a more optimistic picture. Postponed retirement disproportionately favors training incentives and skills of older workers which enhances their employability.

The life-cycle pattern in Figure 5 points to the different unemployment incidence for young and old workers. Unemployment among younger workers falls quite sharply, by 1.5 percentage points for the 20-29 years-old. The main reason is the elimination of unemployment benefits from the contribution base as well as stronger monitoring as part of active labor market policy. A stronger tax-benefit link also encourages job search and reduces unemployment. Unemployment among older workers, in contrast, is hardly affected at all. Delaying actual retirement by about four years amounts to a strong increase of labor supply which prevents a more significant reduction in the unemployment rate. By international comparison, old age unemployment still remains very low. The present framework does not lend support to the view that postponing retirement is ineffective because older workers might be difficult to employ. 
Figure 5: Life-Cycle Unemployment

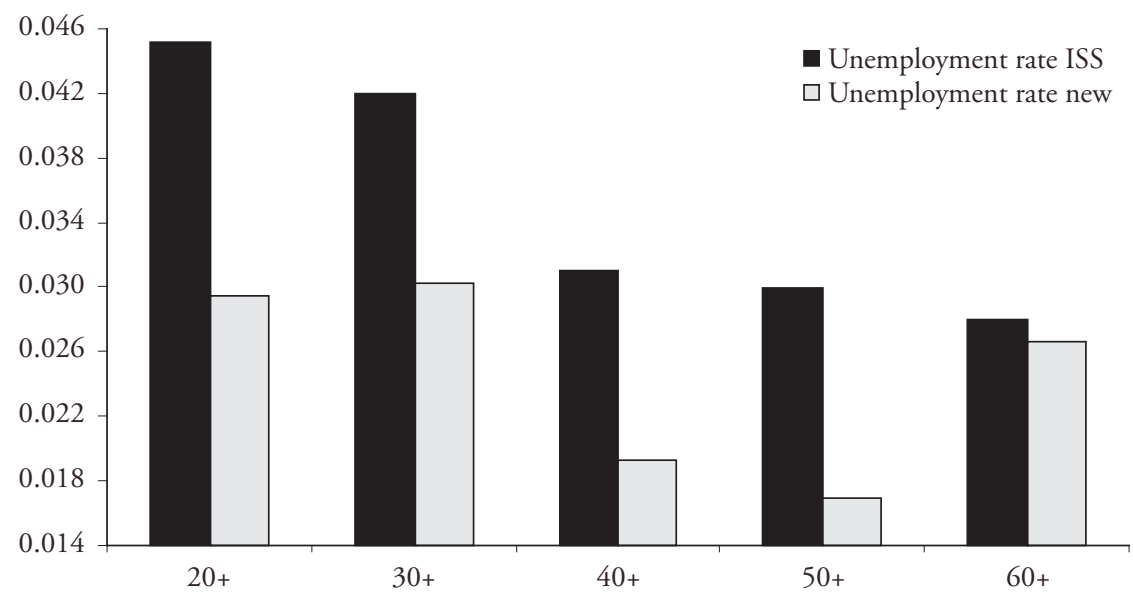

\subsection{Transitional Adjustment}

Table 3 reports long-run values. However, short- and medium-run effects are of special interest to policy makers. Given that demographic change is a slow process extending over several decades, policy measures should also be introduced with roughly the same speed. Hence, our scenario gradually implements reform according to $y_{t}=y_{\infty}+\left(y_{0}-y_{\infty}\right) \times 0.95^{t}$ where $y$ is an element of the policy package with value $y_{0}$ in the initial equilibrium and $y_{\infty}$ after complete implementation. The adjustment speed 0.95 implies a half-life of $t_{0.5} \approx 13.5$ years, i.e. half of the policy change is completed within 13.5 years, half of the remaining part takes another 13.5 years etc. We refrain from any more elaborate transition strategies. Public debt and real public spending are kept constant in per capita terms. The response to policy shocks and aging can easily lead to non-monotonic adjustment since demographic change with overlapping generations, economic adjustment such as savings, investment and skill formation, and gradual policy implementation occur at different speeds. Figure 6 shows that the old-age dependency ratio may take 6 to 10 decades to fully adjust. The horizontal axis measures time (in years) after the reform.

The economic dependency ratio is the ratio of retired to active persons and is rather more important for fiscal balance and economic performance than the demographic dependency ratio which is the ratio of persons older than 65 over 
Figure 6: Demographic and Economic Dependency Ratio

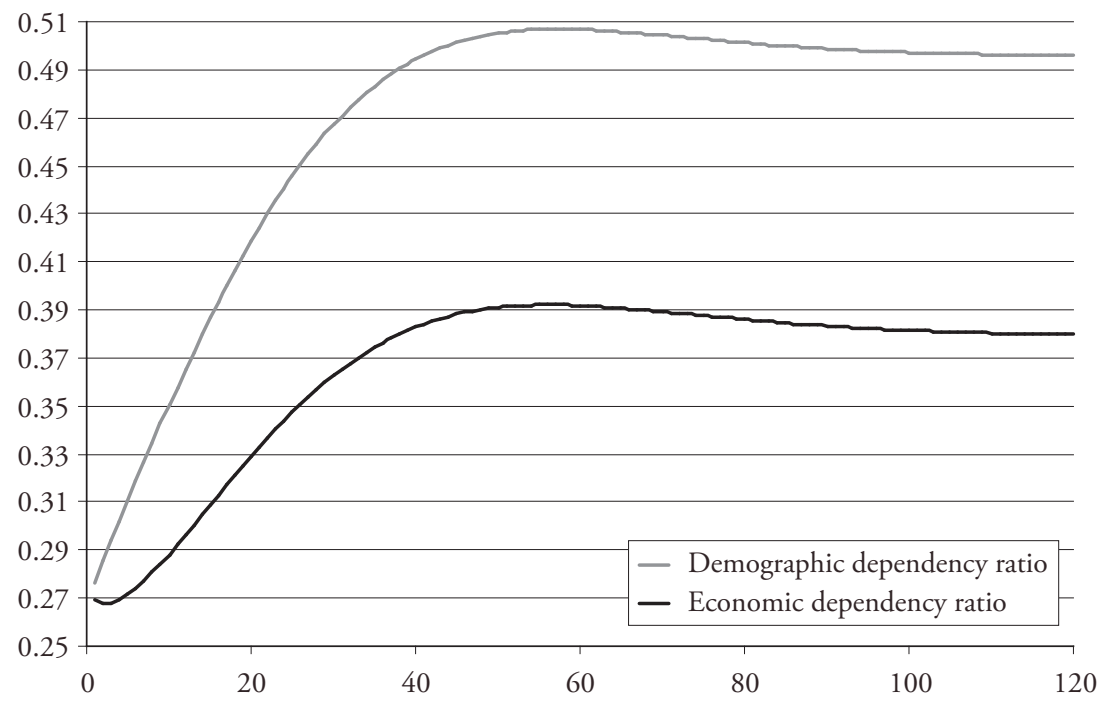

younger ones. As Figure 6 illustrates, the large increase in retirement age adds additional workers, shrinks the number of retired persons and, thereby, squeezes the economic dependency ratio by about 12 percentage points in the long-run. The value for tax rates and employment gains in Figure 7 converge to the longrun values listed in Table 3. Given the delayed implementation, there is no policy change at all in period zero, but the anticipation of improved labor market incentives in future periods leads to an immediate, endogenous increase in the retirement age and old age participation rate from 0.4 to 0.43 . Together with other labor supply responses, effective employment jumps up by $0.7 \%$, allowing an instantaneous cut in the wage tax rate and employer plus employee contribution rates to the PAYG pillar by -0.2 percentage points.

When the policy changes slowly set in, the retirement age rises and ultimately boosts the participation rate among 60-69 years old to 81\%, up from 40\% initially. Accordingly, the increase in the economic dependency ratio in Figure 6 is much less dramatic than the rise in the demographic ratio. Although policy changes are only gradually phased in, they are still 'too fast' to some extent, boosting labor market incentives by more than what would be required to prevent a change in tax and contribution rates. Accordingly, tax rates significantly fall in a first adjustment phase to a maximum of 0.7 percentage points 
Figure 7: Wage Tax, PAYG Contributions and Employment

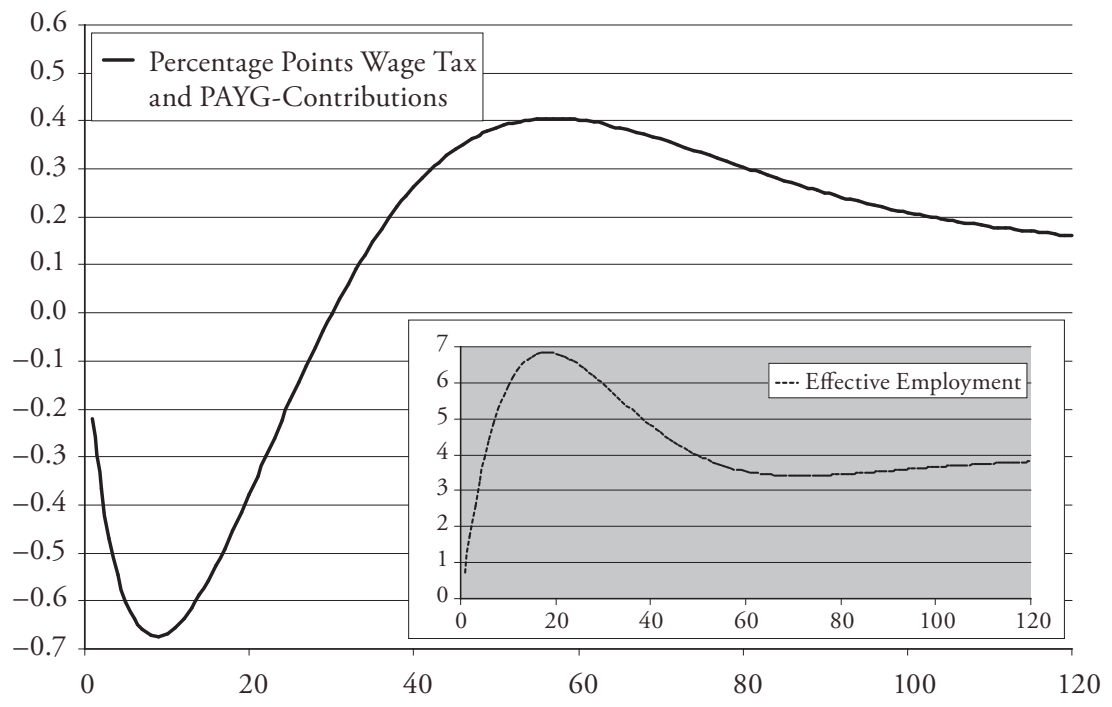

in period 9, or a total of 2 points if the wage tax rate and the employer and employee contribution rates to the PAYG pillar are taken together. The employment rate overshoots in a first phase, leading to a maximum gain of $6.8 \%$ in period 18 before the economy approaches a long-run equilibrium with more moderate employment gains as reported in Table 3. In general, it is difficult to devise a phasing-in policy that would completely avoid any non-monotonic or overshooting adjustment in labor market behavior due to overly fast or too slow policy implementation. In principle, it would also be possible to use debt policy to smooth tax rates over time and to distribute employment gains more evenly across generations.

\section{Conclusions}

A longer life in good health is one of the great gifts of medical advancement. At the same time, increased longevity induces a large demographic change which creates difficult challenges in financing social security and could substantially reduce per capita income. The old-age dependency ratio will approximately double and the population is expected to grow by $10 \%$ until 2050 . One may safely expect 
that a shock of this scale will have important repercussions on economic performance. In this study, we have used a rich computational model of life-cycle labor supply, unemployment and retirement, explicitly including the separate PAYG and funded pillars of the Swiss pension system, to quantify the potential economic impact of aging in Switzerland. When benefit rules are kept constant and the government follows a passive policy of raising wage taxes and social security contributions to achieve fiscal balance, the consequences might be rather bleak. Simulations show that the labor tax burden might need to rise by 22 percentage points and per capita income could fall by roughly the same amount, compared to the status quo without aging and reform.

Such a scenario is neither politically realistic nor reasonable but may be used as a reference point. We have found that a comprehensive policy approach can largely alleviate the unfavorable consequences of aging on per capita income. The financing of social security with largely the same replacement rates as today might require only a moderately higher tax burden. By far the most important measure is an increase in retirement age by about 4 years so that longer lived future generations roughly split their extended total life-time between work and retirement in the same way as present generations must do. The comprehensive policy approach investigated in this paper includes further structural reform of the pension system and other measures to stimulate training and labor market performance. All in all, the simulation results show that this reform package could limit the increase of the tax burden to 4 percentage points of value added tax and keep the loss in per capita income to a moderate $6 \%$. To put this number in perspective, a period of zero growth over 3-4 years relative to continued trend growth would yield the same decline in per capita income.

\section{References}

Abrahamsen, Yngve, and Jochen Hartwig (2003), Volkswirtschaftliche Auswirkungen verschiedener Demographieszenarien und Varianten zur langfristigen Finanzierung der Alterssicherung in der Schweiz, Forschungsbericht Nr. $12 / 03$.

Altig, David, and Charles T. Carlstrom (1999), "Marginal Tax Rates and Income Inequality in a Life-Cycle Model", American Economic Review, 89, pp. 1197-1215.

Altig, David, Alan J. Auerbach, Laurence J. Kotlikoff, Kent A. Smetters and Jan Walliser (2001), "Simulating Fundamental Tax Reform in the United States”, American Economic Review, 91, pp. 574-595. 
Atrinson, Anthony, and John Micklewright (1991), "Unemployment Compensation and Labor Market Transitions: A Critical Review", Journal of Economic Literature, 29, pp. 1679-1727.

Belot, Michele, and Jan van Ours (2001), "Unemployment and Labor Market Institutions: An Empirical Analysis", Journal of the Japanese and International Economies, 15, pp. 403-418.

Blanchard, Olivier J. (1985), "Debt, Deficits and Finite Horizons", Journal of Political Economy, 93, pp. 223-247.

Blanchard, Olivier J., and Justin Wolfers (2000), "The Role of Shocks and Institutions in the Rise of European Unemployment: The Aggregate Evidence", Economic Journal, 110, pp. 1-33.

Blundell, Richard (1995), "The Impact of Taxation on Labor Force Participation and Labor Supply”, in: OECD Job Study: Taxation, Employment, and Unemployment, Paris.

Blundell, Richard, and Thomas MaCurdy (1999), "Labor Supply: A Review of Alternative Approaches", in: O. Ashenfelter and D. Card (eds), Handbook of Labor Economics, Vol. 3A, New York.

Börsch-Supan, Axel (2000), "Incentive Effects of Social Security on Labor Force Participation: Evidence in Germany and Across Europe”, Journal of Public Economics, 78, pp. 25-49.

Börsch-Supan, Axel, and Joachim K. Winter (2001), "Population Aging, Savings Behavior, and Capital Markets", NBER Working Paper 8561.

Bovenberg, Lans A. (2003), "Financing Retirement in the European Union", International Tax and Public Finance, 10, pp.713-734.

Bovenberg, Lans A., and Thijs Knaap (2005), "Ageing, Funded Pensions and the Dutch Economy”, CESifo Working Paper 1403.

Bundesamt Für Statistik (2006), Szenarien zur Bevölkerungsentwicklung in der Schweiz.

Bundesrat (2008), Bericht des Bundesrats über seine Geschäftsführung 2007.

Bütler, Monika (2009), "Switzerland: High Replacement Rates and Generous Subsistence as a Barrier to Work in Old Age", Geneva Papers on Risk and Insurance, 34, pp. 561-577.

Bütler, Monika, Olivia Huguenin and Federica Teppa (2004), "What Triggers Early Retirement? Results from Swiss Pension Funds”, CEPR Discussion Paper 4394.

Crémer, Helmuth, and Pierre Pestienu (2003), "The Double Dividend of Postponing Retirement", International Tax and Public Finance, 10, pp.419-434.

Diamond, Peter A. (2004), "Social Security", American Economic Review, 94, pp. 1-24. 
Diamond, Peter A., and Peter R. Orszag (2005), "Saving Social Security", Journal of Economic Perspectives, 19, pp. 11-32.

Disney, Richard (2004), "Are Contributions to Public Pension Programmes a Tax on Employment?", Economic Policy, 39, pp. 269-311.

Dorn, David, and Alfonso Sousa-Poza (2010), "Voluntary and Involuntary Early Retirement: An International Analysis", Applied Economics, 42, pp. 427-438.

Eissa, Nada, and Hilary W. Hoynes (2004), "Taxes and the Labor Market Participation of Married Couples: the Earned Income Tax Credit", Journal of Public Economics, 88, pp. 1931-1958.

Farmer, Roger E.A. (1990), "Rince Preferences", Quarterly Journal of Economics, 105, pp. 43-60.

Feldstein, Martin (2005a), "Rethinking Social Insurance", American Economic Review, 95, pp. 1-24.

Feldstein, Martin (2005b), "Structural Reform of Social Security", Journal of Economic Perspectives, 19, pp. 33-55.

Feldstein, Martin and Jefrrey B. Liebman (2002), "Social Security", in: A. J. Auerbach, M. Feldstein (ed.), Handbook of Public Economics, Vol. 4, Amsterdam, pp. 2245-2324.

Feldstein, Martin, and Andrew Samwick (1992), "Social Security Rules and Marginal Tax Rates”, National Tax Journal, 45, pp. 1-22.

Feldstein, Martin, and Andrew Samwick (2002), Potential Paths of Social Security Reform, Cambridge, pp. 181-224.

Fenge, Robert, and Pierre Pestieau (2005), Social Security and Early Retirement, Cambridge.

Fisher, Walter. H., and Christian Keuschnigg (2010), "Pension Reform and Labor Market Incentives”, Journal of Population Economics, 23, pp. 769-803.

Fouarge, Didier, and Trudie Schils (2009), "The Effect of Early Retirement Incentives on the Training Participation of Older Workers", LABOUR, 23, pp. 85-109.

Gerfin, Michael, and Michael Lechner (2002), "A Microeconometric Evaluation of the Active Labour Market Policy in Switzerland", Economic Journal, 112, pp. 854-893.

Gerfin, Michael, Michael Lechner and Heidi Steiger (2005), "Does Subsidised Temporary Employment Get the Unemployed Back to Work? An Econometric Analysis of Two Different Schemes", Labour Economics, 12, pp. 807-835.

Gertler, Mark (1999), "Government Debt and Social Security in a Life-Cycle Economy”, Carnegie-Rochester Conference Series on Public Policy, 50, pp.61-110. 
Görlitz, Katja (2009), "The Effect of Subsidizing Continuous Training Investments - Evidence from German Establishment Data", Ruhr Economic Papers 144.

Grafenhofer, Dominik, Christian Jaag, Christian Keuschnigg and Mirela Keuschnigg (2007), "Economic Ageing and Demographic Change". Vienna Yearbook of Population Research 2007, pp. 133-165.

Gruber, Jonathan, and David A. Wise (1999), Social Security and Retirement Around the World, Chicago.

Gruber, Jonathan, and David A. Wise (2004) (ed.), Social Security Programs and Retirement around the World: Micro-Estimation, Chicago.

Gruber, Jonathan, and David A. Wise (2007), Social Security Programs and Retirement Around the World: Fiscal Implications, Chicago.

Immervoll, Herwig, Henrik J. Kleven, Claus T. Kreiner and Emmanuel SaEz (2007), "Welfare Reform in European Countries: A Microsimulation Analysis", Economic Journal, 117, pp. 1-44.

JaAg, Christian (2009), "Education, Demographics, and the Economy", Journal of Pension Economics and Finance, 8, pp. 189-223.

Jaag, Christian, Christian Keuschnigg and Mirela Keuschnigg (2010), "Pension Reform, Retirement and Life-Cycle Unemployment", International Tax and Public Finance, 17 (5), pp. 556-585.

Kalemli-Ozcan, Sebnem (2002), "Does the Mortality Decline Promote Economic Growth?", Journal of Economic Growth, 7, pp. 411-439.

Kane, Thomas (2006), "Public Intervention and Post-Secondary Education", in: E. Hanushek and F. Welch (ed.), Handbook of the Economics of Education, Amsterdam.

Keuschnigg, Christian, and Mirela Keuschnigg (2004), "Aging, Labor Markets and Pension Reform in Austria", Finanzarchiv, 60, pp.359-392.

Keuschnigg, Christian, and Mirela Keuschnigg (2010), "Training, LifeCycle Unemployment, and Retirement: Technical Appendix”, Universität St. Gallen, unpublished manuscript.

Keuschnigg, Christian, Mirela Keuschnigg and Christian JaAg (2010), "Aging and the Financing of Social Security in Switzerland: An Analytical Note”, Universität St. Gallen, unpublished manuscript.

Kotlikoff, Laurence J. (1997), "Privatizing Social Security in the United States: Why and How”, in: A. J. Auerbach (ed.), Fiscal Policy. Lessons from Economic Research, Cambridge, pp. 213-248.

Krueger, Alan, and Bruce Meyer (2002), "Labor Supply Effects of Social Insurance", in: A. Auerbach and M. Feldstein (ed.), Handbook of Public Economics, Vol. 4, Amsterdam, pp. 2327-2392. 
Lau, Morten, and Panu Poutvaara (2006), "Social Security Incentives and Human Capital Investment”, Finnish Economic Papers, 19, pp. 16-24.

Layard, Richard, Stephen Nickell and Richard Jackman (1991), Unemployment, London.

Lieb, Christoph, Andre Müller and Renger van Nieuwroop (2003), Analyse der Finanzierungsquellen für die AHV SWISSOLG - Ein Overlapping Generations Model für die Schweiz, Forschungsbericht Nr. 11/03.

Lindbeck, Assar, and Mats Persson (2003), "The Gains from Pension Reform”, Journal of Economic Literature, 41, pp. 74-112.

Meghir, Costas, and David Phillips (2008), "Labor Supply and Taxes", IFS Working Paper 08/04.

Messer, Dolores, and Stefan Wolter (2009), "Money Matters — Evidence from a Large-Scale Randomized Field Experiment with Vouchers for Adult Training", CESifo Working Paper 2548.

Miles, David (1999), "Modelling the Impact of Demographic Change Upon the Economy”, Economic Journal, 109, pp. 1-36.

Mitchell, Olivia S., and John W. Phillips (2000), "Retirement Responses to Early Social Security Benefit Reductions”, NBER Working Paper 7963.

Nickel, Stephen (1997), "Unemployment and Labor Market Rigidities: Europe versus North America”, Journal of Economic Perspectives, 3, pp. 55-74.

Queisser, Monika, and Edward Whitehouse (2006), "Neutral or Fair? Actuarial Concepts and Pension-System Design", OECD Social, Employment and Migration WP No. 40.

Queisser, Monika, and Dimitri Vittas (2000), "The Swiss Multi-Pillar Pension System: Triumph of Common Sense?”, Policy Research Working Paper 2416, The World Bank.

Scarpetta, Stefano (1996), "Assessing the Role of Labour Market Policies and Institutional Settings on Unemployment: A Cross-Country Study", OECD Economic Studies, 26, pp.43-98.

Soares, Rodrigo R. (2005), "Mortality Reductions, Educational Attainment, and Fertility Choice", American Economic Review, 95, pp. 580-601.

Weil, Philippe (1990), "Nonexpected Utility in Macroeconomics", The Quarterly Journal of Economics, Vol. 105, No. 1, pp. 29-42.

Weil, David N. (2006), "Population Aging”, NBER Working Paper 12147. 


\section{SUMMARY}

The gains in life expectancy are expected to double the dependency ratio and increase population by $10 \%$ in Switzerland until 2050. To quantify the effects on social security and public finances, we use an overlapping generations model with five margins of labor supply: labor market participation, hours worked, job search, retirement, and on-the-job training. A passive fiscal strategy would be very costly. A comprehensive reform, including an increase in the retirement age to 68 years, may limit the tax increases to 4 percentage points of value added tax and reduce the decline of per capita income to less than $6 \%$. 